\title{
Experimental investigation and prediction of tribological behavior of unidirectional short castor oil fiber reinforced epoxy composites
}

\author{
Rajesh EGALA ${ }^{1}$, G V JAGADEESH ${ }^{2}$, Srinivasu Gangi SETTI ${ }^{1, *}$ \\ ${ }^{1}$ Department of Mechanical Engineering, National Institute of Technology Raipur, Chhattisgarh 492010, India \\ ${ }^{2}$ Department of Mechanical Engineering, Gudlavalleru Engineering College, Gudlavalleru, Andhra Pradesh 521356, India \\ Received: 14 March 2019 / Revised: 07 May 2019 / Accepted: 28 September 2019 \\ (C) The author(s) 2019.
}

\begin{abstract}
The present study aims at introducing a newly developed natural fiber called castor oil fiber, termed ricinus communis, as a possible reinforcement in tribo-composites. Unidirectional short castor oil fiber reinforced epoxy resin composites of different fiber lengths with $40 \%$ volume fraction were fabricated using hand layup technique. Dry sliding wear tests were performed on a pin-on-disc tribometer based on full factorial design of experiments (DoE) at four fiber lengths $(5,10,15$, and $20 \mathrm{~mm})$, three normal loads $(15,30$, and $45 \mathrm{~N})$, and three sliding distances $(1,000,2,000$, and 3,000 m). The effect of individual parameters on the amount of wear, interfacial temperature, and coefficient of friction was studied using analysis of variance (ANOVA). The composite with $5 \mathrm{~mm}$ fiber length provided the best tribological properties than 10, 15, and $20 \mathrm{~mm}$ fiber length composites. The worn surfaces were analyzed under scanning electron microscope. Also, the tribological behavior of the composites was predicted using regression, artificial neural network (ANN)-single hidden layer, and ANN-multi hidden layer models. The confirmatory test results show the reliability of predicted models. ANN with multi hidden layers are found to predict the tribological performance accurately and then followed by ANN with single hidden layer and regression model.
\end{abstract}

Keywords: natural fiber; castor oil fiber; epoxy composite; full factorial design of experiments (DoE); analysis of variance (ANOVA); prediction; regression; artificial neural network (ANN)

\section{Introduction}

In the recent times, there has been an increased usage of polymeric materials for tribological components such as guide rails, plastic gears, sliding bearings, and artificial joints etc., as an alternative to metals [1]. This is due to the desirable characteristics of the polymers such as light weight, self-lubrication, noise reduction, and high productivity. In general, the tribological performance of polymers is further improved by reinforcing fibers, particles, fillers, and whiskers. Among these, natural fibers as reinforcements in polymeric materials have gained new interests for tribological applications because of easy availability, simple fiber extraction process, less weight, inexpensive, and biodegradable. The natural fiber reinforced composites were in great demand in automobile [2, 3] and structural applications [3]. Some of the applications of natural fiber composites in automotive industry and structural industry are shown in Tables 1 and 2, respectively. During the fabrication of natural fiber composites, locally available inexpensive plant fibers can be preferred for tribological applications after analyzing their feasibility.

With numerous applications, it is important to study the tribological performance of natural fiber reinforced polymer composites. Table 3 shows the tribological studies on various natural fiber reinforced polymer composites at different material parameters and operating conditions, also for few synthetic fibers were discussed.

Apart from fiber volume fraction, orientation, and

* Corresponding author: Srinivasu Gangi SETTI, E-mail: nivassetti@gmail.com 
Table 1 Applications of natural fiber reinforced composites in automotive industry [3].

\begin{tabular}{ccl}
\hline Model & $\begin{array}{c}\text { Original equipment } \\
\text { manufacturer (OEM) }\end{array}$ & \multicolumn{1}{c}{ Applications } \\
\hline 3, 5, and 7 series & BMW & $\begin{array}{l}\text { Seat back, headliner, door, noise insulation panels, moulded foot well } \\
\text { lining, and boot-lining }\end{array}$ \\
A2, A3, A4, A6, and A8 & Audi & $\begin{array}{l}\text { Seat back, side and back door panels, boot and spare tire-lining, and hat rack } \\
\text { Door panel }\end{array}$ \\
Alfa romeo 146, 156, and 159 & Fiat & Rear storage shelf and panel \\
ES3 & Rover & Pillar garnish and other interior parts \\
Toyota & Seat back, door panel, boot-liner, and boot-lid panel \\
Chevrolet trail blazer, & General motors & Seat back and cargo area floor mat \\
ccdillac de ville & &
\end{tabular}

Table 2 Natural fiber reinforced composite applications in various industries [3].

\begin{tabular}{cl}
\hline Fiber & \multicolumn{1}{c}{ Applications } \\
\hline Hemp & Construction, textiles, paper, packaging, furniture, cordage, geotextiles, and electrical \\
Sisal & Paper, pulp, and construction such as doors, panels, roofing sheets, and shutting plate \\
Kenaf & Packaging, insulations, mobile cases, bags, animal bedding, soilless potting mixes, oil, and liquid absorbent materials \\
Jute & Building parts such as door frames, shutters, panels, roofing sheets, packaging, transport, geotextiles, and chip boards \\
Oil palm & Building parts such as door frames, windows, insulated panels, fencing, siding, decking, and roofing \\
Flax & Railing systems, fencing, decking, tennis racket, snowboarding, bicycle frame, seat post, fork, and laptop cases \\
Cotton & Textile, yarn, furniture, cordage, and transport \\
\hline
\end{tabular}

Table 3 Tribology study of fiber reinforced composites.

\begin{tabular}{|c|c|c|c|c|c|}
\hline Researchers & Polymer & Fiber & Parameters ${ }^{*}$ & Responses $^{*}$ & Ref. \\
\hline Dwivedi and Chand & Polyester & Jute & $\mathrm{FO}, \mathrm{NL}$ & SWR, CoF, Temp & [4] \\
\hline Bajpai et al. & Polylactic acid (PLA) & Nettle, sisal & NL, SD, SV & SWR, CoF & {$[5]$} \\
\hline Basumatary et al. & Epoxy & Ipomoea carnea & FVF, NL, SD & AW, SWR & {$[6]$} \\
\hline Nirmal et al. & Epoxy & Bamboo & $\mathrm{FO}, \mathrm{NL}, \mathrm{SD}, \mathrm{SV}$ & SWR, CoF & [7] \\
\hline Chin and Yousif & Epoxy & Kenaf & $\mathrm{FO}, \mathrm{NL}, \mathrm{SD}, \mathrm{SV}$ & SWR, CoF, Temp & {$[8]$} \\
\hline Rashid et al. & Phenolic & Sugar palm & FT, NL, SD & $\mathrm{AW}, \mathrm{CoF}$ & [9] \\
\hline Shalwan and Yousif & Epoxy & Date palm & FVF, F, NL, SV & SWR, CoF & {$[10]$} \\
\hline Yousif et al. & Polyester & Betelnut & $\mathrm{NL}, \mathrm{SD}$ & SWR, CoF, Temp & [11] \\
\hline Chand and Dwivedi & Polyester & Sisal & FVF, FT, NL & AW, CoF, Temp & [12] \\
\hline Shuhimi et al. & Epoxy & Oil palm, kenaf & FVF, NL & SWR, CoF, Temp & {$[13]$} \\
\hline Liu et al. & Nitrile butadiene & Corn stalk & FT, Temp & $\mathrm{WR}, \mathrm{CoF}$ & [14] \\
\hline Kumar et al. & Epoxy & Grewia optiva / Bauhinia vahlii & FVF, SV, NL, SD & SWR & [15] \\
\hline Patel et al. & Polyester & Sour-weed & FL, FVF & SWR & [16] \\
\hline Pattanaik et al. & Epoxy & Fly-ash & FVF, SV, NL & $\mathrm{AW}, \mathrm{CoF}$ & {$[17]$} \\
\hline Khun & Epoxy & Carbon & FVF, NL & $\mathrm{WR}, \mathrm{CoF}$ & {$[18]$} \\
\hline
\end{tabular}

*Note: NL: normal load; SV: sliding velocity; SD: sliding distance; F: filler; FO: fiber orientation; FT: fiber treatment; FVF: fiber volume fraction; CoF: coefficient of friction; AW: amount of wear; SWR: specific wear rate; Temp: temperature.

chemical treatment, fiber length (FL) also plays a key role in enhancing the tribological behavior of natural fiber reinforced polymer composites. For instance, ElTayeb [19-21] employed sugarcane fiber of different lengths for understanding the potential of short chopped fibers (SCF) in enhancing the tribological properties of polyester composites. Composites of fiber length 1, 5, and $10 \mathrm{~mm}$ were fabricated and tested. 
It was found that composite with fiber length of $5 \mathrm{~mm}$ exhibited lower weight loss of $20 \%-50 \%$ compared to other fiber lengths [21]. Mylsamy and Rajendran [22] studied the effect of fiber length on the tribological performance of chopped agave americana fiber reinforced epoxy composites. It was revealed that composites with $3 \mathrm{~mm}$ fiber length provided the best tribological results than those with 5 and $7 \mathrm{~mm}$ fiber length. Boopathi et al. [23] studied the effect of fiber length on the tribological properties of borassus fruit fiber reinforced epoxy composites. The critical length of fiber was found to be $5 \mathrm{~mm}$ among 3,5, and $7 \mathrm{~mm}$ fiber length composites for the best tribological results.

Artificial neural network (ANN) approach, based on biological nervous system, evolved as a fascinating computational tool to simulate a wide variety of complex engineering problems. An extensive literature review was carried out to find the feasibility of ANN to predict the tribological behavior of composites. Table 4 shows few studies on the tribological behavior of composites predicted by ANN.

Observing the tremendous advantages of natural fibers, there is a need to further investigate the possibility of new natural fibers to be used as reinforcement in polymer composites for tribological applications. India is known for abundant natural resources, mostly from agriculture and forest. Castor oil cultivation was widely spread across all parts of India and the $3^{\text {rd }}$ largest producer in the world. Therefore, the castor oil plant stalk will be readily available to extract the fiber at very low cost. The preliminary studies emphasized that castor oil fiber, which was termed as ricinus communis, can be used as a reinforcement in polymer matrix composites based on mechanical, physical, and chemical properties. The main objective of this study was to analyze the tribological behavior of newly developed castor oil fiber reinforced epoxy composites. Also, regression models and ANN models were developed to predict the tribological behavior of composites for unknown data.

\section{Materials and experiments}

\subsection{Fiber extraction}

Castor oil plant stalk was collected from Kompally, Hyderabad, India. The collected stalk was immersed in water at room temperature for nine consecutive days for microbial degradation, such that cortex, xylem, and pith were separated easily. Two fibers extracted were cortex (bark type) fibers and xylem (wood type) fibers. The extracted fibers were dried and mechanically tested. An overview of fiber extraction process followed was mentioned in Fig. 1. Our primary investigation revealed that the tensile strength of a single cortex fiber and single xylem fiber was 323 and $100 \mathrm{MPa}$, respectively. The diameter of cortex fiber was found to be $0.3 \mathrm{~mm}$. Also, the fibers extracted were conditioned at $28{ }^{\circ} \mathrm{C}$ to maintain relative humidity of $65 \%$ before fabrication of samples. As the extracted castor oil cortex fiber length ranges from 6-8 m, it was

Table 4 Tribology results and fatigue behavior of composites predicted using ANN.

\begin{tabular}{|c|c|c|}
\hline Authors & ANN prediction & Ref. \\
\hline Biswal and Satapathy & Specific wear rate of epoxy-palmyra fiber composites & [24] \\
\hline Parikh and Gohil & Wear of cotton fiber polyester composites & {$[25]$} \\
\hline Satapathy et al. & Specific wear rate of $\mathrm{TiO}_{2}$-polyester composites & {$[26]$} \\
\hline Fathy and Megahed & Specific wear rate of $\mathrm{Cu}-\mathrm{Al}_{2} \mathrm{O}_{3}$ nano composite & [27] \\
\hline Jiang et al. & $\begin{array}{l}\text { Specific wear rate and CoF of short glass fiber and carbon fiber reinforced polyamide composites } \\
\text { with PTFE and graphite fillers }\end{array}$ & [28] \\
\hline Canakci et al. & Specific wear rate and volume loss of B $\mathrm{B}_{4} \mathrm{C} / \mathrm{AA} 2014 \mathrm{MMC}$ 's & {$[29]$} \\
\hline Stojanović & Wear rate and $\mathrm{CoF}$ of $\mathrm{Al} / \mathrm{SiC} / \mathrm{Gr}$ hybrid composites & [30] \\
\hline $\begin{array}{l}\text { Saravanan and } \\
\text { Senthilkumar }\end{array}$ & Wear rate and $\mathrm{CoF}$ of rice husk ash reinforced aluminum alloy composites & [31] \\
\hline Kranthi and Satapathy & Specific wear rate of pine wood dust reinforced epoxy composites & [32] \\
\hline Hassan et al. & Bending fatigue behavior of glass fiber/polyester composite shafts & [33] \\
\hline
\end{tabular}



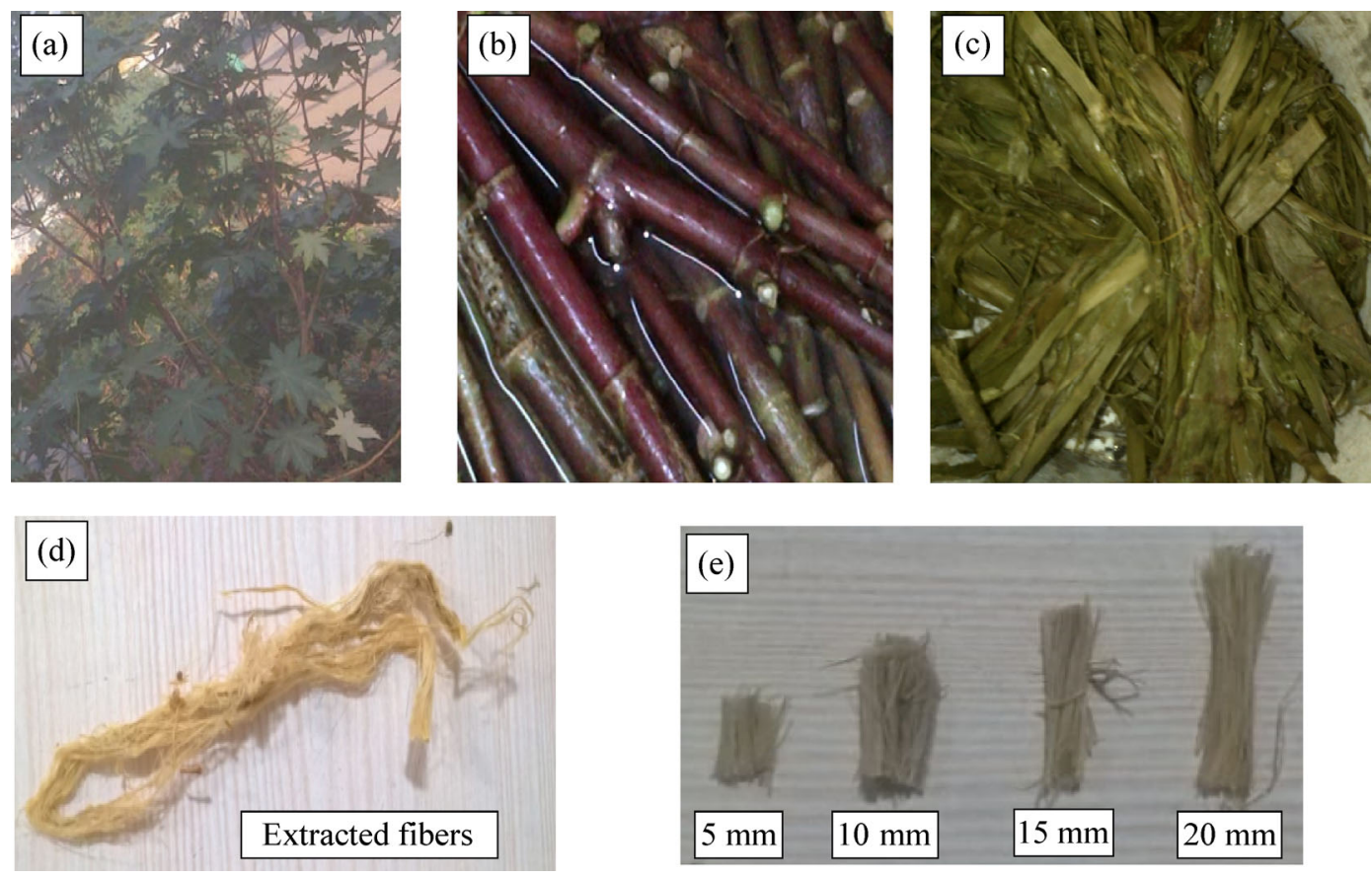

Fig. 1 Fiber extraction procedure. (a) Castor oil plant, (b) stems immersed in water, (c) stems after immersion, (d) extracted fibers, and (e) chopped fibers.

chopped into lengths of 5, 10, 15, and $20 \mathrm{~mm}$ respectively for fabricating the short fiber composites.

\subsection{Resin}

The matrix material, epoxy is a thermosetting polymer that polymerizes and cross links, when mixed with a hardener. With addition of hardener, epoxy can be made flexible or rigid, transparent or colored, and also for setting extremely fast or slow. The degree of wetting during the composite fabrication process is highly important for strong adhesion between matrix and fiber. Epoxy grade (LY556) and hardener grade (HY 951) were used for fabrication of unidirectional epoxy composites. Matrix and hardener were mixed in the ratio 10:1 by weights as used by Basumatary et al for fabricating ipomoea carnea reinforced epoxy composites [6].

\subsection{Fabrication of composites}

Manual hand layup process was used for fabrication of unidirectional short castor oil fiber reinforced epoxy composites [11]. As mentioned earlier, the tensile strength of cortex fiber was much greater than that of xylem fiber. Hence, castor oil cortex fibers were preferred over xylem fibers to achieve better mechanical and tribological properties. The composites were fabricated with $40 \%$ volume fraction of cortex fiber with fiber lengths 5, 10, 15, and $20 \mathrm{~mm}$, respectively.

\subsection{Tribology setup}

The tribological behavior of fabricated castor oil fiber reinforced epoxy composites was investigated using pin on disc tribometer supplied by DUCOM. The schematic diagram of pin on disc tribometer was shown in Fig 2. Dry sliding wear experiments were performed as per the American Society for Testing and Materials (ASTM) G 99 standard. The specimens were fixed in a specimen holder with one face sliding

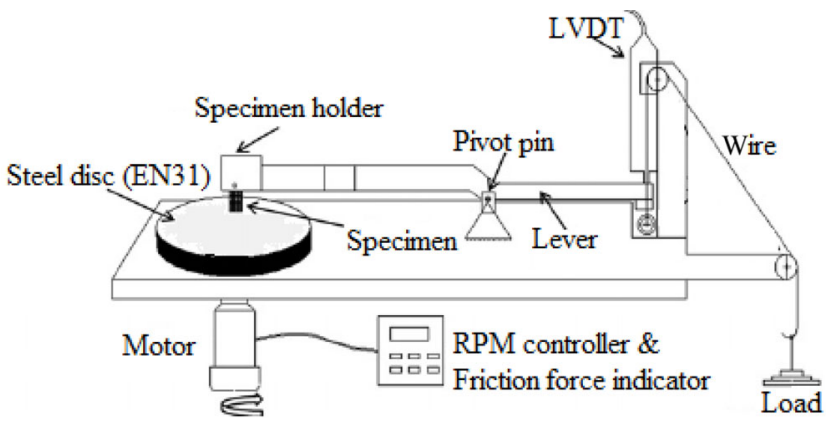

Fig. 2 Schematic of pin on disc tribometer. 
over the disc. The contour surface is a hardened EN-31 steel disc with hardness $69 \mathrm{HRC}$, surface roughness $0.6 \mu \mathrm{m}$ and thickness $8 \mathrm{~mm}$. The required load on to the pin is applied by means of pulley in the range of 15,30 , and $45 \mathrm{~N}$. The rotations per minute (RPM) are set to constant at 500 and the track diameters are set to 100,110 , and $120 \mathrm{~mm}$ to achieve the sliding distances of 1,000, 2,000, and 3,000 m, respectively, by adjusting the running time successively. Initial roughness of disc surface and specimens are maintained by rubbing against emery papers of grit sizes 220 and 600 respectively such that the initial roughness was in the range of $R_{a} 0.02$ to $0.07 \mu \mathrm{m}$ for the disc and $R_{a} 0.33$ to $0.45 \mu \mathrm{m}$ for the specimen. The samples are weighed before and after the experiment to estimate the amount of wear.

\subsection{Experimental plan and responses}

Design of experiment is a powerful tool for modeling and analyzing the influence of control factors (input parameters) on output performances. The tribology tests on the fabricated composites were performed under different operating conditions considering three parameters, fiber length, normal load, and sliding distance. Fiber length was varied at four levels, and the other two parameters such as load and sliding distance were varied at three levels. The three parameters with different levels were listed in Table 5. Conventional full factorial design of experiments was deployed for the experimentation. The full factorial list of experiments and their corresponding output responses are tabulated in Table 6. Each test was repeated twice. The results from each trail and also, the mean of the results were represented in Table 6.

Table 5 Factors and their corresponding levels.

\begin{tabular}{cccccccc}
\hline Factor & Type & Levels & Unit & Level 1 & Level 2 & Level 3 & Level 4 \\
\hline FL & Fixed & 4 & $\mathrm{~mm}$ & 5 & 10 & 15 & 20 \\
Load & Fixed & 3 & $\mathrm{~N}$ & 15 & 30 & 45 & - \\
$\mathrm{SD}$ & Fixed & 3 & $\mathrm{~m}$ & 1,000 & 2,000 & 3,000 & - \\
\hline
\end{tabular}

Table 6 Full factorial design of experiments.

\begin{tabular}{|c|c|c|c|c|c|c|c|c|c|c|c|c|}
\hline \multirow{2}{*}{ No } & \multirow{2}{*}{$\begin{array}{c}\mathrm{FL} \\
(\mathrm{mm})\end{array}$} & \multirow{2}{*}{$\begin{array}{l}\text { Load } \\
(\mathrm{N})\end{array}$} & \multirow{2}{*}{$\begin{array}{l}\text { SD } \\
(\mathrm{m})\end{array}$} & \multicolumn{3}{|c|}{ Wear (mg) } & \multicolumn{3}{|c|}{ Temp $\left({ }^{\circ} \mathrm{C}\right)$} & \multicolumn{3}{|c|}{$\mathrm{CoF}$} \\
\hline & & & & Trail1 & Trail2 & Mean & Traill & Trail2 & Mean & Traill & Trail2 & Mean \\
\hline 1 & 5 & 15 & 1,000 & 2 & 2.1 & 2.05 & 25 & 25 & 25.0 & 0.247 & 0.231 & 0.239 \\
\hline 2 & 5 & 15 & 2,000 & 2.5 & 2.7 & 2.6 & 25 & 25 & 25.0 & 0.258 & 0.243 & 0.251 \\
\hline 3 & 5 & 15 & 3,000 & 3.3 & 3.5 & 3.4 & 25 & 26 & 25.5 & 0.289 & 0.259 & 0.274 \\
\hline 4 & 5 & 30 & 1,000 & 2.7 & 2.9 & 2.8 & 26 & 26 & 26.0 & 0.311 & 0.299 & 0.305 \\
\hline 5 & 5 & 30 & 2,000 & 3.3 & 3.7 & 3.5 & 26 & 27 & 26.5 & 0.323 & 0.319 & 0.321 \\
\hline 6 & 5 & 30 & 3,000 & 4 & 4.2 & 4.1 & 27 & 27 & 27.0 & 0.345 & 0.337 & 0.341 \\
\hline 7 & 5 & 45 & 1,000 & 4.5 & 4.6 & 4.55 & 27 & 27 & 27.0 & 0.371 & 0.365 & 0.368 \\
\hline 8 & 5 & 45 & 2,000 & 4.8 & 5.3 & 5.05 & 27 & 28 & 27.5 & 0.402 & 0.388 & 0.395 \\
\hline 9 & 5 & 45 & 3,000 & 5.5 & 5.8 & 5.65 & 28 & 28 & 28.0 & 0.418 & 0.406 & 0.412 \\
\hline 10 & 10 & 15 & 1,000 & 2.7 & 2.2 & 2.45 & 25 & 25 & 25.0 & 0.256 & 0.233 & 0.245 \\
\hline 11 & 10 & 15 & 2,000 & 3.0 & 3.6 & 3.30 & 25 & 26 & 25.5 & 0.281 & 0.254 & 0.268 \\
\hline 12 & 10 & 15 & 3,000 & 4.0 & 4.3 & 4.15 & 26 & 26 & 26.0 & 0.303 & 0.287 & 0.295 \\
\hline 13 & 10 & 30 & 1,000 & 3.2 & 3.5 & 3.35 & 27 & 26 & 26.5 & 0.332 & 0.305 & 0.319 \\
\hline 14 & 10 & 30 & 2,000 & 4.0 & 4.3 & 4.15 & 27 & 27 & 27.0 & 0.344 & 0.319 & 0.332 \\
\hline 15 & 10 & 30 & 3,000 & 4.6 & 4.8 & 4.70 & 27 & 28 & 27.5 & 0.381 & 0.356 & 0.369 \\
\hline 16 & 10 & 45 & 1,000 & 4.9 & 5.0 & 4.95 & 27 & 28 & 27.5 & 0.405 & 0.388 & 0.397 \\
\hline 17 & 10 & 45 & 2,000 & 5.3 & 5.5 & 5.40 & 27 & 28 & 27.5 & 0.414 & 0.407 & 0.411 \\
\hline 18 & 10 & 45 & 3,000 & 6.2 & 6.4 & 6.30 & 28 & 28 & 28.0 & 0.431 & 0.428 & 0.430 \\
\hline 19 & 15 & 15 & 1,000 & 2.8 & 2.6 & 2.70 & 26 & 26 & 26.0 & 0.283 & 0.267 & 0.275 \\
\hline
\end{tabular}




\begin{tabular}{|c|c|c|c|c|c|c|c|c|c|c|c|c|}
\hline \multirow{3}{*}{ No } & \multirow{3}{*}{$\begin{array}{c}\mathrm{FL} \\
(\mathrm{mm})\end{array}$} & \multirow{3}{*}{$\begin{array}{l}\text { Load } \\
(\mathrm{N})\end{array}$} & \multirow{3}{*}{$\begin{array}{l}\text { SD } \\
(\mathrm{m})\end{array}$} & \multirow{2}{*}{\multicolumn{3}{|c|}{ Wear (mg) }} & \multirow{2}{*}{\multicolumn{3}{|c|}{ Temp $\left({ }^{\circ} \mathrm{C}\right)$}} & \multicolumn{3}{|c|}{ (Continued) } \\
\hline & & & & & & & & & & & $\mathrm{CoF}$ & \\
\hline & & & & Traill & Trail2 & Mean & Traill & Trail2 & Mean & Traill & Trail2 & Mean \\
\hline 20 & 15 & 15 & 2,000 & 3.5 & 3.3 & 3.40 & 26 & 26 & 26.0 & 0.302 & 0.297 & 0.300 \\
\hline 21 & 15 & 15 & 3,000 & 3.7 & 3.5 & 3.60 & 26 & 27 & 26.5 & 0.324 & 0.308 & 0.316 \\
\hline 22 & 15 & 30 & 1,000 & 4.0 & 4.0 & 4.00 & 27 & 27 & 27.0 & 0.341 & 0.333 & 0.337 \\
\hline 23 & 15 & 30 & 2,000 & 4.5 & 4.9 & 4.70 & 27 & 27 & 27.0 & 0.38 & 0.369 & 0.375 \\
\hline 24 & 15 & 30 & 3,000 & 5.0 & 5.7 & 5.35 & 28 & 28 & 28.0 & 0.41 & 0.391 & 0.401 \\
\hline 25 & 15 & 45 & 1,000 & 5.4 & 5.8 & 5.60 & 28 & 28 & 28.0 & 0.421 & 0.407 & 0.414 \\
\hline 26 & 15 & 45 & 2,000 & 5.8 & 6.2 & 6.00 & 28 & 29 & 28.5 & 0.446 & 0.424 & 0.435 \\
\hline 27 & 15 & 45 & 3,000 & 6.2 & 6.5 & 6.35 & 29 & 29 & 29.0 & 0.453 & 0.437 & 0.445 \\
\hline 28 & 20 & 15 & 1,000 & 2.8 & 2.8 & 2.80 & 26 & 27 & 26.5 & 0.305 & 0.305 & 0.305 \\
\hline 29 & 20 & 15 & 2,000 & 3.6 & 3.6 & 3.60 & 27 & 27 & 27.0 & 0.311 & 0.309 & 0.310 \\
\hline 30 & 20 & 15 & 3,000 & 3.8 & 3.8 & 3.80 & 27 & 27 & 27.0 & 0.351 & 0.339 & 0.345 \\
\hline 31 & 20 & 30 & 1,000 & 4.0 & 4.2 & 4.10 & 27 & 28 & 27.5 & 0.382 & 0.367 & 0.375 \\
\hline 32 & 20 & 30 & 2,000 & 5.0 & 4.1 & 4.55 & 28 & 28 & 28.0 & 0.391 & 0.376 & 0.384 \\
\hline 33 & 20 & 30 & 3,000 & 5.5 & 5.3 & 5.40 & 28 & 29 & 28.5 & 0.4 & 0.403 & 0.402 \\
\hline 34 & 20 & 45 & 1,000 & 5.0 & 6.2 & 5.60 & 28 & 29 & 28.5 & 0.442 & 0.428 & 0.435 \\
\hline 35 & 20 & 45 & 2,000 & 6.0 & 6.7 & 6.35 & 29 & 29 & 29.0 & 0.464 & 0.446 & 0.455 \\
\hline 36 & 20 & 45 & 3,000 & 6.5 & 6.6 & 6.55 & 30 & 30 & 30.0 & 0.472 & 0.465 & 0.469 \\
\hline
\end{tabular}

\section{Results and discussion}

The one of the objectives of reinforcing polymers with natural fibers was to enhance the tribological properties of the polymers. Fiber volume fraction, length, and orientation were the key constituents of polymer composites, to reduce the amount of wear, coefficient of friction, and interfacial temperature. The volume fraction of fiber considered was $40 \mathrm{vol} \%$. The excessive addition of fiber i.e. above $40 \mathrm{vol} \%$ resulted in the fiber pulling out from the resin during the test due to poor wetting and interfacial adhesion [6]. It was revealed that the wear performance was much superior in normal orientation of natural fiber compared to parallel and anti-parallel orientations [7]. The normal orientation of fiber will be obtained only for unidirectional samples while performing tribology tests using pin on disc tribometer as the sample is fixed normal to the rotating steel counter face. Hence, $40 \mathrm{vol} \%$ fraction of unidirectional short castor fiber reinforced epoxy composites were used for this study. The input parameters considered for the study are fiber length, load, and sliding distance. The output responses evaluated were amount of wear, $\mathrm{CoF}$, and interfacial temperature.

\subsection{Effect of input parameters on the amount of wear}

The primary investigation revealed that the amount of wear is unpredictable when the applied load is low $(5$ or $10 \mathrm{~N})$. Therefore, the lowest amount of wear can be measured with an applied load of $15 \mathrm{~N}$. At this loading condition, less penetration with counter surface was observed resulting in less amount of wear. As the load increased gradually, the amount of wear increased proportionally and can be seen in main effects plot of Fig. 3. This is due to the higher amount of penetration and deeper grooves created, resulting in high material removal by ploughing. Also, the wear mechanism of the composites at higher loads was predominated by micro and macro-cracks in the epoxy regions and de-bonding of fibers. As the fiber length was increased gradually, the amount of wear also proportionally increased and can be seen in main effects plot of Fig. 3. The $5 \mathrm{~mm}$ length fiber composite produced better wear performance due to strong interfacial bonding between the matrix and the fiber. The sample with fiber length $20 \mathrm{~mm}$ has weight loss about 3 times higher than that of $5 \mathrm{~mm}$ 

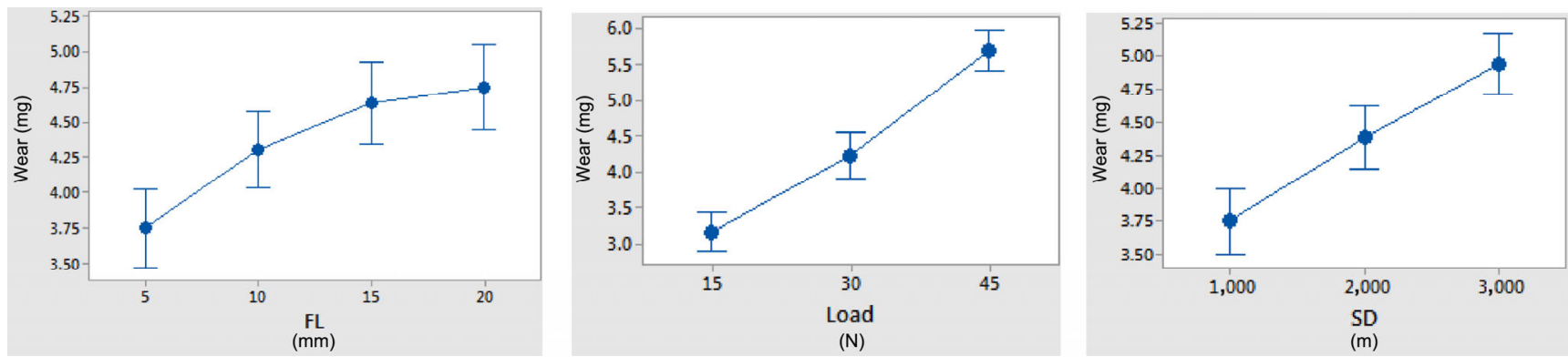

Fig. 3 Main effects plot for wear.

length fiber under similar operating conditions. Increasing fiber length from 5 to $20 \mathrm{~mm}$ increased the amount of wear. The similar behavior of wear was observed by Mylsamy and Rajendran [22] for short agave americana fiber reinforced epoxy resin composites and Boopathi et al. [23] for borassus fruit fiber reinforced epoxy resin composites. The $5 \mathrm{~mm}$ length fibers provided more hindrance along the path of the sliding direction than 10, 15, and $20 \mathrm{~mm}$ fiber length and resisted the movement of wear particles [22]. This may emphasize, that the critical fiber length can be close to $5 \mathrm{~mm}$, at which, the lowest amount of wear was attained. The chemical compatibility of matrix bonding, mechanical properties of fiber, and fiber length play a major role in reducing the amount of wear. It is clear that, minimum amount of wear occurs at $5 \mathrm{~mm}$ length, is a favorable length to establish the cross linking of the polymer quite well, resulting in high tribological performance. Therefore, it can be concluded that the increased wear performance of $5 \mathrm{~mm}$ fiber length at an optimum load could be possibly due to a fiber rich surface, high chemical bonding, and high cross linking, thereby protecting the contacting composite surface and minimizing wear of the matrix.

Figure 4 shows the wear behavior with interaction effects. As seen in the interaction plots, at a particular fiber length, the amount of wear increases with increase in sliding distance and load. At a particular load, the amount of wear increases with increase in fiber length and sliding distance. The weak bonding between the fiber and the matrix facilitates the easier removal of fiber at longer sliding distance and fiber length. At a particular sliding distance, the amount of wear increases with increase in fiber length and load because of weak bonding and high penetration respectively. The rate of wear decreased for $20 \mathrm{~mm}$ fiber length with increase in sliding distance. This might be

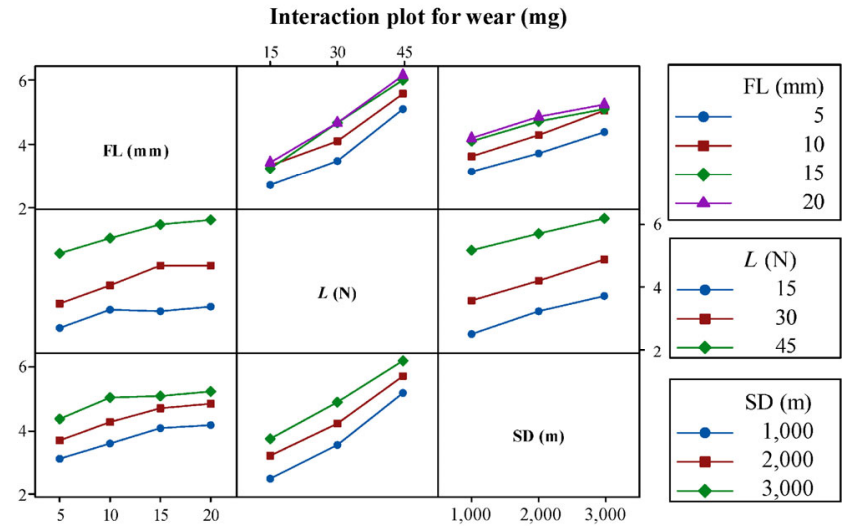

Fig. 4 Interaction plot for wear.

due to the wear debris that filled the space between the contacting surfaces, reduced the depth of penetration in the composite. Based on the full factorial experimental data, the lowest wear of $2.09 \mathrm{mg}$ was obtained for following combinations: fiber length $5 \mathrm{~mm}$, load $15 \mathrm{~N}$, and sliding distance $1,000 \mathrm{~m}$, and the highest of $6.55 \mathrm{mg}$ was obtained for combinations: fiber length $20 \mathrm{~mm}$, load $45 \mathrm{~N}$, and sliding distance 3,000 m.

The influence of each input parameter on the amount of wear was analyzed. The percentage contribution of fiber length, load, and sliding distance on the amount of wear of unidirectional castor oil reinforced epoxy composites was analyzed using a statistical analysis of variance method. Table 7 shows the ANOVA results for the amount of wear. ANOVA analysis presented in this paper was carried out at $5 \%$ significance level and 95\% confidence level. The calculated probability values for all the input parameters is 0.000 . Since all the probabilities are below 0.05 . It implies that all the input parameters i.e., load, fiber length, and sliding distance have a significant effect on the amount of wear. Meanwhile, the $P$-value of lack of fit is nonsignificant as it is more than 0.05 . Therefore, the analysis obtained based on experimental data is 
Table 7 Analysis of variance for the amount of wear.

\begin{tabular}{ccccccc}
\hline Source & DF & Adj SS & Adj MS & $\begin{array}{c}F- \\
\text { value }\end{array}$ & $\begin{array}{c}P \text { - } \\
\text { value }\end{array}$ & $\begin{array}{c}\% \\
\text { Cont }\end{array}$ \\
\hline FL (mm) & 1 & 10.067 & 10.0668 & 99.97 & 0.000 & 9.0 \\
Load (N) & 1 & 77.521 & 77.5208 & 769.84 & 0.000 & 69.4 \\
SD (m) & 1 & 17.280 & 17.2800 & 171.60 & 0.000 & 15.5 \\
Error & 68 & 6.847 & 0.1007 & - & - & 6.1 \\
$\begin{array}{c}\text { Lack- } \\
\text { of-fit }\end{array}$ & 32 & 3.997 & 0.1249 & 1.58 & 0.093 & - \\
$\begin{array}{c}\text { Pure } \\
\text { error }\end{array}$ & 36 & 2.850 & 0.0792 & - & - & - \\
Total & 71 & 111.715 & - & - & - & 100 \\
\hline
\end{tabular}

Note: DF-Degrees of freedom; Adj SS-Adjusted sum of squares; Adj MSAdjusted mean of squares; \% Cont-Percentage contribution.

significant. It was observed that the load contributed by $69 \%$, sliding distance by $15 \%$, and fiber length by $9 \%$. Therefore, the most significant parameter on the amount of wear was load followed by sliding distance, fiber length, and others.

\subsection{Effect of input parameters on the interfacial temperature}

It was evident that the incorporation of natural fibers in a thermosetting polymer enhances the thermal stability of the polymer. This is due to the higher thermal conductivity of fibers than that of the polymer matrix. Therefore, the improved thermal stability of natural fiber reinforced epoxy composites prevents the surface film transfer to the counter surface. The experiments were conducted at room temperature $\left(25^{\circ} \mathrm{C}\right)$. The main effects plot for interfacial temperature is shown in Fig. 5. Due to increase in the applied normal load, the interfacial temperature increases due to the increase in frictional heat with increase in load. The higher interfacial temperature was found at the highest applied load $45 \mathrm{~N}$, which is about $30^{\circ} \mathrm{C}$. Interfacial temperature increased with increase in fiber length. Highest interfacial temperature is found in case of $20 \mathrm{~mm}$ fiber length, which can be directly linked with coefficient of friction. The same phenomenon was observed for kenaf fiber reinforced epoxy composites [8] and jute fiber reinforced polyester composites [4].

Figure 6 shows the interfacial temperature behavior with interaction effects. As seen in the interaction plots, at a particular fiber length, the interfacial temperature increases with increase in sliding distance and load because of high frictional force. The frictional forces increased with increase in load and fiber length. The temperature of the specimen at interface increases by $0-3{ }^{\circ} \mathrm{C}$ for 5 and $10 \mathrm{~mm}$ fiber length, $1-4{ }^{\circ} \mathrm{C}$ for $15 \mathrm{~mm}$ fiber length, and $2-5^{\circ} \mathrm{C}$ for $20 \mathrm{~mm}$ fiber length, respectively. At a particular load, the interfacial temperature increases with increase in fiber length and sliding distance. Similarly, at a particular sliding distance, the interfacial temperature increases with increase in fiber length and load. Hence, it can be concluded that there is no significant rise in interfacial temperature and it is witnessed physically as there are no softening characteristics of specimens observed during experimentation. Based on the full factorial experimental data, no change in interface temperature was obtained for following combinations: fiber length $5 \mathrm{~mm}$, load $15 \mathrm{~N}$, and sliding distance 1,000 m, and the highest change of $5{ }^{\circ} \mathrm{C}$ was obtained for combinations: fiber length $20 \mathrm{~mm}$, load $45 \mathrm{~N}$, and sliding distance 3,000 $\mathrm{m}$. Therefore, $5 \mathrm{~mm}$ fiber length can be considered as a critical fiber length for the lowest interfacial temperature. This might be due to high thermal conductivity in $5 \mathrm{~mm}$ fiber length composite than other combinations tested.
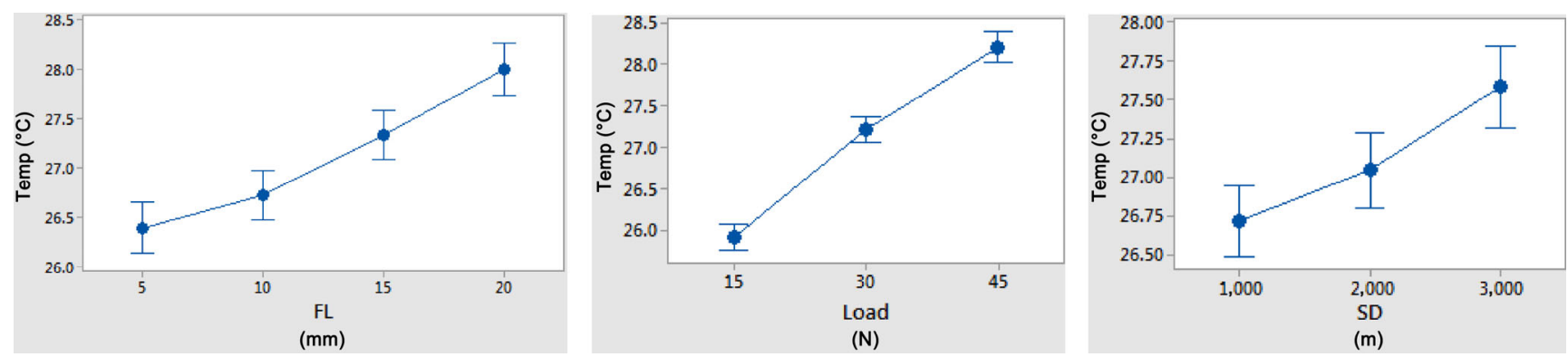

Fig. 5 Main effects plot for interfacial temperature. 


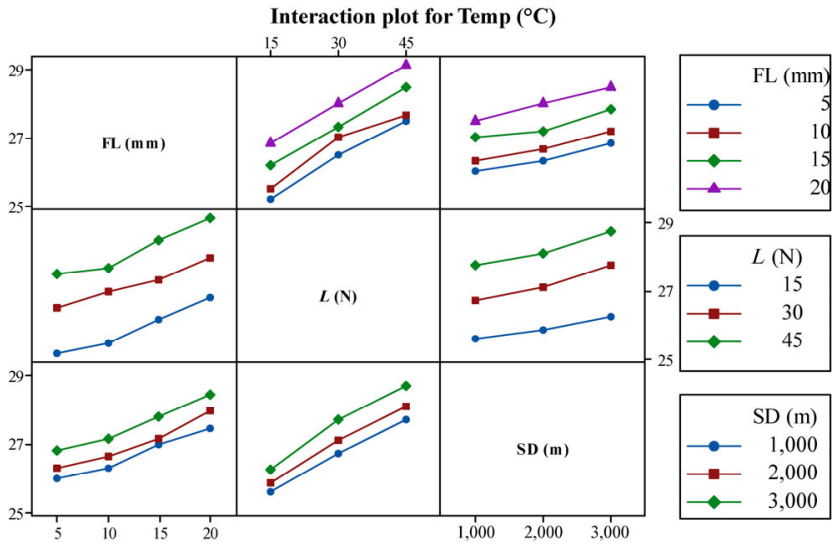

Fig. 6 Interaction plot for interfacial temperature.

The influence and the percentage contribution of each control parameter i.e., fiber length, load, and sliding distance on the interfacial temperature were analyzed using a statistical analysis of variance method. Table 8 shows the ANOVA results for the interfacial temperature. The probability value for all the input parameters is 0.000 . Since all the probabilities are below 0.05 , it implies that all the input parameters i.e., load, fiber length, and sliding distance have a significant effect on the interfacial temperature. Meanwhile, the $P$-value of lack of fit is non-significant as it is more than 0.05 . Therefore, the analysis obtained based on experimental data is quite reliable. It was observed that the load contributed by $58 \%$, fiber length by $24 \%$, and sliding distance by $8 \%$. Therefore, the most significant parameter on the interfacial temperature was load followed by fiber length, sliding distance, and others.

\subsection{Effect of input parameters on CoF}

Generally, a higher CoF of epoxy polymer is due to

Table 8 Analysis of variance for interfacial temperature.

\begin{tabular}{ccccccc}
\hline Source & DF & Adj SS & Adj MS & $\begin{array}{c}F- \\
\text { value }\end{array}$ & $\begin{array}{c}P- \\
\text { value }\end{array}$ & \% Cont \\
\hline FL (mm) & 1 & 26.678 & 26.6778 & 177.42 & 0.000 & 24.4 \\
Load (N) & 1 & 63.021 & 63.0208 & 419.11 & 0.000 & 57.7 \\
SD (m) & 1 & 9.188 & 9.1875 & 61.10 & 0.000 & 8.4 \\
Error & 68 & 10.225 & 0.1504 & - & - & 9.4 \\
$\begin{array}{c}\text { Lack- } \\
\text { of-fit }\end{array}$ & 32 & 3.225 & 0.1008 & 0.52 & 0.969 & - \\
$\begin{array}{c}\text { Pure } \\
\text { error }\end{array}$ & 36 & 7.000 & 0.1944 & - & - & - \\
Total & 71 & 109.111 & - & - & - & 100 \\
\hline
\end{tabular}

larger contact between the polymer and its counterpart during dry sliding. Therefore, incorporation of short natural fiber on the surface can lower the CoF of the epoxy composite by reducing the direct contact between the polymer and steel disc. The main effects plot for the $\mathrm{CoF}$ is shown in Fig. 7. As the applied load gradually increased from 15 to $45 \mathrm{~N}$, the $\mathrm{CoF}$ of the epoxy composite increased proportionally due to increase in frictional forces at the interface. As the fiber length increases, the CoF of the epoxy composite also increases. Increase in the $\mathrm{CoF}$ of the composite material with increase in fiber length can be attributed to the toughness of the composite material. The toughness of the natural fiber composite material increases with increase in fiber length. As shown in Fig. 7, the CoF reduces due to decrease in the fiber length from 20 to $5 \mathrm{~mm}$. The similar behavior of CoF was observed by Mylsamy and Rajendran [22] for chopped agave americana fiber reinforced epoxy composites and Boopathi et al. [23] for borassus fruit fiber reinforced epoxy composites. The surface of $5 \mathrm{~mm}$ fiber length specimen acted as a protective layer by reducing the mechanical interlocking at the interface, thus reducing the $\mathrm{CoF}$ [1]. As the sliding distance increased from 1,000 to 3,000 $\mathrm{m}$, the CoF of the epoxy composite also increased. The primary investigation revealed that the fluctuation in the CoF of the epoxy composite was highly significant at prolonged sliding distance, which indicates pronounced stick-slip phenomenon with promoted adhesion and wear of the epoxy. Hence, the sliding distance is limited to $3,000 \mathrm{~m}$.

The interaction plots for $\mathrm{CoF}$ for all levels of the input parameters were presented in Fig. 8. As seen in the interaction plots, at a particular fiber length, $\mathrm{CoF}$ increases with increase in sliding distance and load because of prompted adhesive wear and high intermechanical locking respectively. At a particular load, $\mathrm{CoF}$ increases with increase in fiber length and sliding distance. This is due to weakening of surface protective layer and adhesion of polymer. At a particular sliding distance, CoF increases with increase in fiber length and load because of low fiber ends and high intermechanical locking respectively. Based on the full factorial experimental data, the minimum $\mathrm{CoF}$ of 0.239 was associated with the following combination of factors: fiber length $5 \mathrm{~mm}, 15 \mathrm{~N}$ load, and 1,000 m sliding distance, and the highest of 0.469 for the 

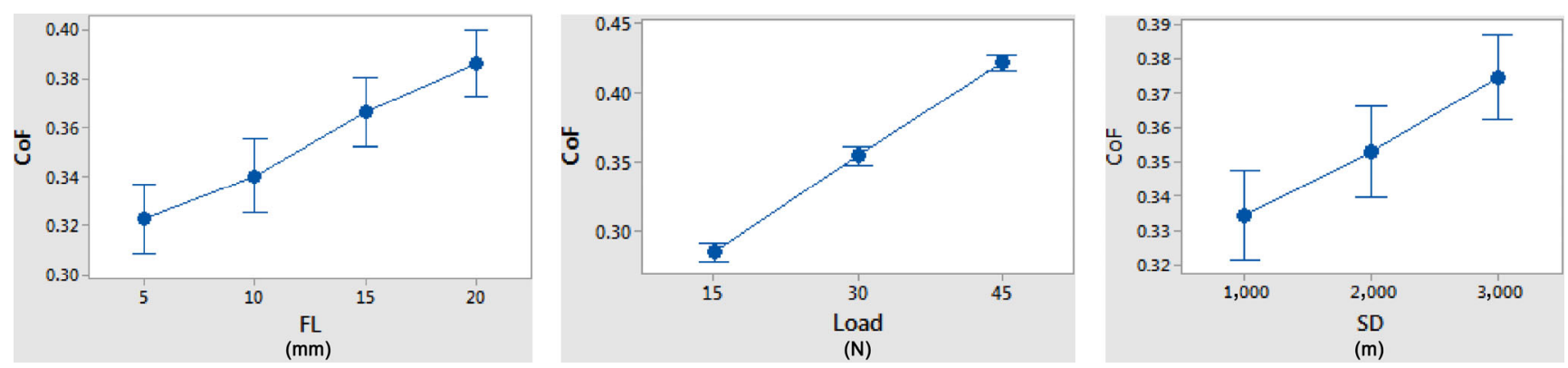

Fig. 7 Main effect plots for $\mathrm{CoF}$.

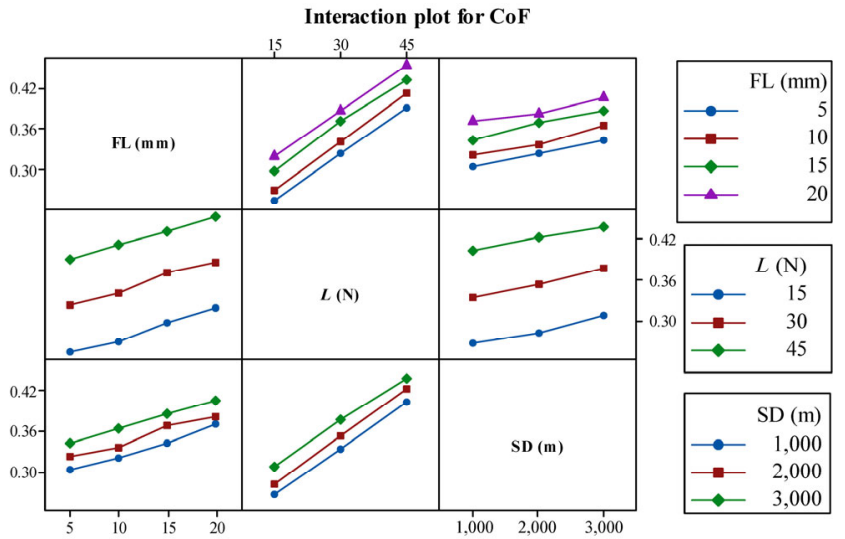

Fig. 8 Interaction plot for $\mathrm{CoF}$.

combination: fiber length $20 \mathrm{~mm}, 45 \mathrm{~N}$ Load, and 3,000 $\mathrm{m}$ sliding distance. The above discussions conclude that the critical fiber length for better $\mathrm{CoF}$ is $5 \mathrm{~mm}$. This is because of protective fiber rich surface at interface, which in turn lead to reduced mechanical interlocking.

The influence and the percentage contribution of each input parameter i.e., fiber length, load, and sliding distance on $\mathrm{CoF}$ were analyzed using a statistical analysis of variance method. Table 9 shows the ANOVA

Table 9 Analysis of variance of CoF.

\begin{tabular}{ccccccc}
\hline Source & DF & Adj SS & Adj MS & $\begin{array}{c}F- \\
\text { value }\end{array}$ & $\begin{array}{c}P- \\
\text { value }\end{array}$ & \% Cont \\
\hline FL (mm) & 1 & 0.042337 & 0.042337 & 411.31 & 0.000 & 14.4 \\
Load (N) & 1 & 0.224954 & 0.224954 & $2,185.49$ & 0.000 & 76.5 \\
SD (m) & 1 & 0.019562 & 0.019562 & 190.05 & 0.000 & 6.6 \\
$\begin{array}{c}\text { Error } \\
\text { Lack- } \\
\text { of-fit }\end{array}$ & 68 & 0.006999 & 0.000103 & - & - & 2.5 \\
$\begin{array}{c}\text { Pure } \\
\text { error }\end{array}$ & 36 & 0.004508 & 0.000125 & - & - & - \\
Total & 71 & 0.293852 & - & - & - & 100 \\
\hline
\end{tabular}

results for CoF. The probability value for all the input parameters is 0.000 . Since all the probabilities are below 0.05 , it implies that all the input parameters have a significant effect on CoF. Meanwhile, the $P$-value of lack of fit is non-significant as it is more than 0.05 . Therefore, the data obtained from experiments is highly significant. It was observed that the load contributed by $76 \%$, fiber length by $14 \%$, and sliding distance by $6 \%$. Therefore, the most significant parameter on the interfacial temperature was load followed by fiber length, sliding distance, and others.

\subsection{Comparison of tribological properties for $5 \mathrm{~mm}$ fiber length composites and pure epoxy}

The experimental analysis reveals that 5-mm fiber length composites exhibited better tribological performance. As a result, a comparative study was performed for pure epoxy and $5 \mathrm{~mm}$ fiber length unidirectional castor oil reinforced epoxy composites at extreme chosen tribological conditions such as load $45 \mathrm{~N}$ and sliding distance $3,000 \mathrm{~m}$. The results for lower and higher extreme conditions were presented in Tables 10 and 11, respectively. At lower extreme conditions, addition of $40 \mathrm{vol} \%$ unidirectional short $5 \mathrm{~mm}$ fiber length castor oil fibers improved the wear of epoxy by $58.66 \%$, CoF by $40.40 \%$, and interfacial temperature by $19.35 \%$. At higher extreme conditions, addition of $40 \mathrm{vol} \%$ unidirectional short $5 \mathrm{~mm}$ fiber length castor oil fibers improved the wear of epoxy by $40.46 \%$, CoF by $30.64 \%$, and interfacial temperature by $24.32 \%$.

\subsection{Worn surface analysis}

The information about tribo-failure of short natural fiber reinforced polymer composite is important to exploit its use in industrial applications. The micrographs of the worn surfaces at different fiber lengths, 
Table 10 Comparison of results at test condition: load $15 \mathrm{~N}$ and sliding distance $1,000 \mathrm{~m}$.

\begin{tabular}{ccccccc}
\hline Specimen & \multirow{2}{*}{$\begin{array}{c}\text { Wear } \\
(\mathrm{mg})\end{array}$} & CoF & \multirow{2}{*}{$\begin{array}{c}\text { Temp } \\
\left({ }^{\circ} \mathrm{C}\right)\end{array}$} & & \multicolumn{3}{c}{ \% Improvement } \\
\cline { 5 - 7 } & & & Wear & CoF & Temp \\
\hline Pure epoxy & 6.91 & 0.401 & 31 & & & \\
$\begin{array}{c}5 \text { mm FL } \\
\text { composite }\end{array}$ & 2.03 & 0.239 & 25 & & & \\
\hline
\end{tabular}

Table 11 Comparison of results at test condition: load $45 \mathrm{~N}$ and sliding distance $3,000 \mathrm{~m}$.

\begin{tabular}{|c|c|c|c|c|c|c|}
\hline \multirow{2}{*}{ Specimen } & \multirow{2}{*}{$\begin{array}{l}\text { Wear } \\
(\mathrm{mg})\end{array}$} & \multirow{2}{*}{$\mathrm{CoF}$} & \multirow{2}{*}{ Temp $\left({ }^{\circ} \mathrm{C}\right)$} & \multicolumn{3}{|c|}{$\%$ Improvement } \\
\hline & & & & Wear & $\mathrm{CoF}$ & Temp \\
\hline Pure epoxy & 16.49 & 0.594 & 37 & & & \\
\hline $\begin{array}{l}5 \mathrm{~mm} \mathrm{FL} \\
\text { composite }\end{array}$ & 5.65 & 0.412 & 28 & 65.74 & 30.64 & 24.32 \\
\hline
\end{tabular}

normal loads, and sliding distances of unidirectional short castor oil fiber reinforced epoxy composites were presented in Fig. 9, respectively. Generally, tribofailure of polymer composites proceeds by fiber wear, fiber fracture, matrix wear, and interfacial debonding [22]. Figure 9(a) shows the worn surface morphology of $5 \mathrm{~mm}$ fiber length composite at normal load $45 \mathrm{~N}$ and sliding distance 2,000 $\mathrm{m}$. It was very clear from the micrograph that the fiber offered tremendous resistance to wear relative to matrix, as it can be evident from the distinct wear tracks in matrix while mild wear tracks were observed in fiber. This can be attributed to the high strength of castor oil fiber, well entanglement of fiber at $5 \mathrm{~mm}$ fiber length, fiber rich surface, and high interfacial bonding.
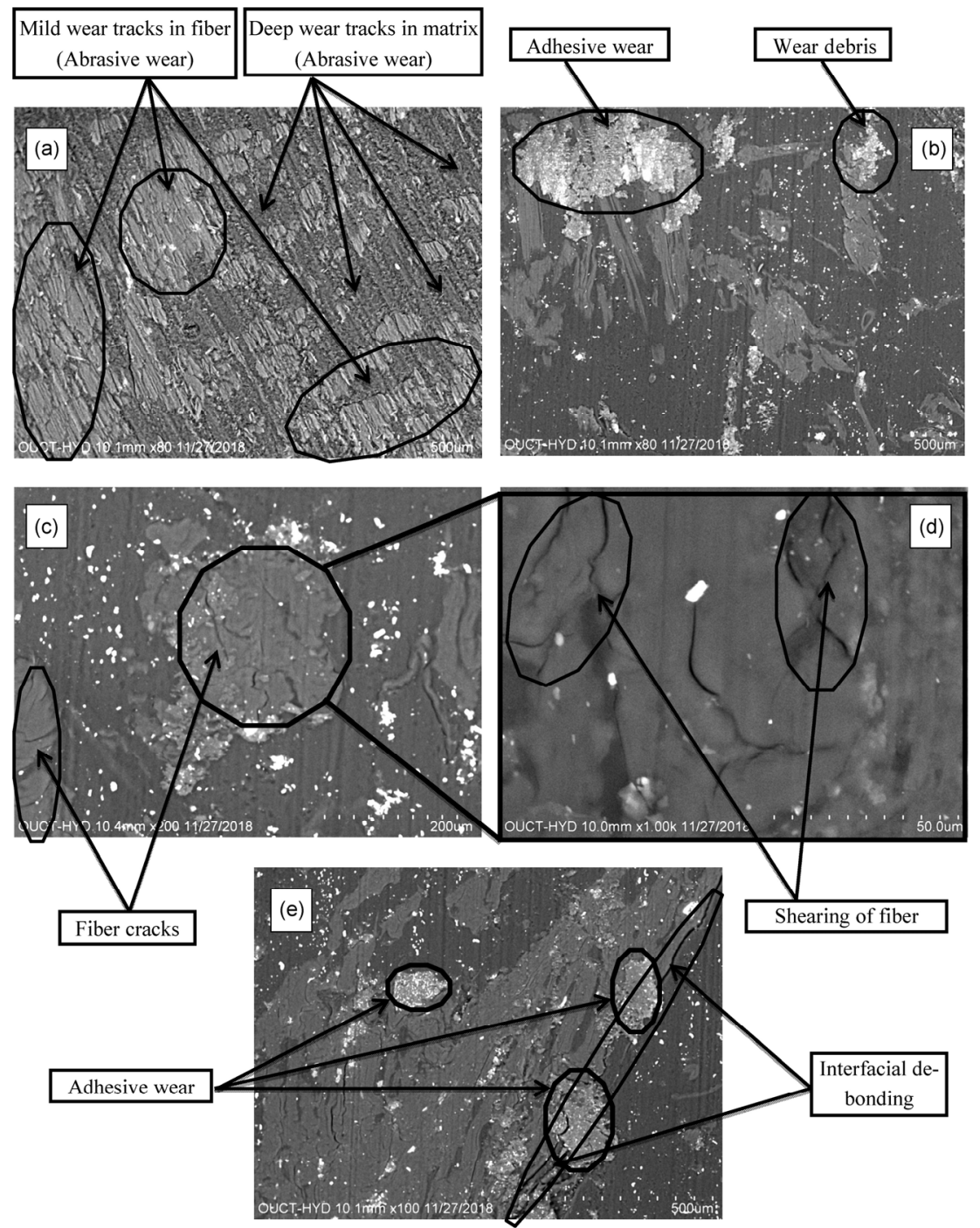

Fig. 9 Worn surface SEM micrographs of composites for the conditions: (a) FL-5 mm, NL-45 N, SD-2,000 m; (b) FL-10 mm, NL-30 N, SD-3,000 m; (c) FL-15 mm, NL-45 N, SD-1,000 m; (d) magnified image of (c); and (e) FL-20 mm, NL-15 N, SD-1,000 m. 
Evidently, $5 \mathrm{~mm}$ fiber length castor oil fiber offered more abrasion wear resistance and well embedded in the matrix. Figure 9(b) depicts the adhesive and abrasive wear of $10 \mathrm{~mm}$ fiber length composite at $30 \mathrm{~N}$ normal load and 3,000 m sliding distance. At higher loads and sliding distances, the degree of abrasion and adhesion was very high. This was due to the abrasive particles (wear debris), that were penetrated into the surface, created more grooves resulting in more material removal by severe plastic deformation. As a result of ploughing, the polymer material transfers and adheres along the wear tracks. Similar behavior was reported for $7 \mathrm{~mm}$ fiber length agave americana/ epoxy composites [22].

The fiber cracks and fiber failure for $15 \mathrm{~mm}$ fiber length composites at normal load $45 \mathrm{~N}$ and 1,000 m sliding distance were depicted in Figs. 9(c) and 9(d). The castor oil fibers were highly fractured and sheared, resulting in lower wear performance. The similar phenomenon was observed for $10 \mathrm{~mm}$ fiber length sugarcane fiber reinforced polyester composites [21]. Figure 9(e) depicts the interfacial de-bonding between epoxy matrix and castor oil fiber reinforcement for $20 \mathrm{~mm}$ fiber length at normal load $15 \mathrm{~N}$ and sliding distance $1,000 \mathrm{~m}$. The poor entanglement of fiber and high fiber bending resulted in lower mechanical bond between matrix and fiber for $20 \mathrm{~mm}$ fiber length composites. As a result, high amount of wear and low wear resistance was observed for $20 \mathrm{~mm}$ fiber length composites even at the lowest tribological condition as well. The effect was much more pronounced at higher tribological conditions.

The worn surface analysis clearly embarks that the lowest fiber length i.e., $5 \mathrm{~mm}$ provides the best wear resistant surface for tribological applications. This can be attributed to the fact that $5 \mathrm{~mm}$ fiber length provides high entanglement, fiber rich surface, high fiber ends, and high bonding strength at $40 \%$ volume fraction of castor oil fiber.

\subsection{Prediction of results}

\subsubsection{Linear regression}

The relationship between the FL, NL, and $\mathrm{SD}$ on amount of wear, temperature, and CoF of the $40 \mathrm{vol} \%$ unidirectional castor oil fiber reinforced epoxy composites was obtained by linear regression analysis. The calculated probability values for all the input parameters is 0.000 . Since all the probabilities are below 0.05 , this means that the developed regression equations are significant. Meanwhile, the $P$-value of lack of fit is non-significant as it is more than 0.05 and can be seen in Table 12. The determination coefficient, $R^{2}$ indicates the goodness of fit. $R^{2}$ for all the output parameters is summarized in Table 13. In this case, the value of the determination coefficient, $R^{2}=0.93$ for the amount of wear, $R^{2}=0.90$ for interfacial temperature, and $R^{2}=$ 0.97 for coefficient of friction indicates that only $3 \%-10 \%$ of the total variations are not explained by these models. The regression equations developed are presented in Table 14. Therefore, the models developed have high goodness of fit. From the regression equations, it is evident that the fiber length, normal load, and sliding distance have positive coefficients for all the output responses. A positive coefficient of fiber length indicates that the tribological performance of fiber reinforced epoxy composite gets deteriorated with increase in fiber length. The same conclusions are reported for short agave americana fiber and borassus fruit fiber reinforced epoxy resin composites in Refs. [22, 23], respectively. But, load is the dominating parameter followed by fiber length and sliding distance. A similar trend was also noticed in the experimental results.

Table 12 Regression model.

\begin{tabular}{cccccc}
\hline Regression & DF & Adj SS & Adj MS & $\begin{array}{c}F- \\
\text { value }\end{array}$ & $\begin{array}{c}P- \\
\text { value }\end{array}$ \\
\hline Wear & 3 & 104.868 & 34.9559 & 347.14 & 0.000 \\
Temp & 3 & 98.886 & 32.9620 & 219.21 & 0.000 \\
CoF & 3 & 0.286852 & 0.095617 & 928.95 & 0.000 \\
\hline
\end{tabular}

Table 13 Model summary.

\begin{tabular}{ccccc}
\hline Output & $S$ & $R$-sq & $R$-sq(adj) & $R$-sq(pred) \\
\hline Wear & 0.317328 & $93.87 \%$ & $93.60 \%$ & $93.13 \%$ \\
Temp & 0.387773 & $90.63 \%$ & $90.22 \%$ & $89.51 \%$ \\
CoF & 0.0101455 & $97.62 \%$ & $97.51 \%$ & $97.36 \%$ \\
\hline
\end{tabular}

Note: S: Standard error; $R$-sq: $R$-square; $R$-sq(adj): Adjusted $R$-square; $R$-sq(pred): Predicted $R$-square.

Table 14 Regression equations

\begin{tabular}{cc}
\hline Output & Equation \\
\hline Wear & $-0.219+0.06689 \mathrm{FL}+0.08472 \mathrm{Load}+0.000600 \mathrm{SD}$ \\
CoF & $0.12243+0.004338 \mathrm{FL}+0.004564 \mathrm{Load}+0.000020 \mathrm{SD}$ \\
Temp & $22.583+0.10889 \mathrm{FL}+0.07639 \mathrm{Load}+0.000438 \mathrm{SD}$ \\
\hline
\end{tabular}




\subsubsection{ANN predictions}

ANN modeling is a mathematical technique, exclusively useful for any correlation that is difficult to simulate with physical models. This is because of its ability to learn and recognize patterns from a series of input and output responses of example cases and reproducibility. In recent years, ANN has been extensively used to predict the tribological [19-27], mechanical [34], and the physical properties [35] of materials. Among the artificial intelligence techniques, ANN was found to provide the best performance in predicting the tribological behavior of materials [36].

It was evident that the tribological behavior of chopped natural fiber reinforced polymer composite materials was mainly related to material properties such as fiber volume fraction, fiber length, fiber orientation, fiber treatment, morphology, and interfacial strength, and operating conditions such as normal load, sliding distance, sliding velocity, temperature, and humidity. Accordingly, interpretation of tribological properties requires a huge experimental data, which consumes time and money extensively. Therefore, the main objective of the present work is to develop the best ANN model to predict the tribological behavior of $40 \mathrm{vol} \%$ unidirectional short castor oil fiber reinforced epoxy resin composites for different fiber lengths, normal loads, and sliding distances other than the experimental data.

Matlab platform was used for ANN training and testing. The inputs to the network were fiber length, load, and sliding distance. The outputs from the network were amount of wear, $\mathrm{CoF}$, and interfacial temperature. Schematic diagram of single hidden layer ANN model constructed in Matlab was shown in Fig. 10. In the present study, the experimental data sets consist of 36 pair of results, which include wear, temperature, and CoF. Among them, a total of 30 results were chosen for training set and 6 results for testing set. Within the training set, the ANN structure divides input and target vectors randomly into three sub sets as follows: $60 \%$ for training, $20 \%$ to validate and to stop training before over fitting, and the last $20 \%$ to provide an independent test of the network. The testing set was used for validating the trained network. Finally, a total of 5 confirmatory experiments were tested to find the performance of the best trained

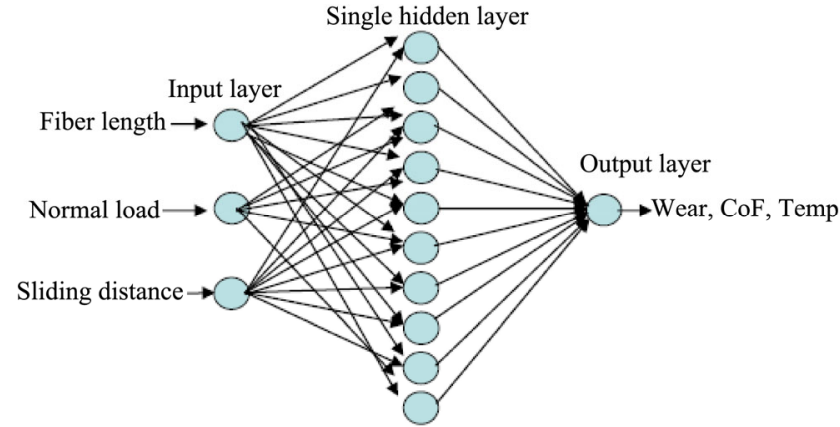

Fig. 10 Schematic of single hidden layer ANN model used in present study.

network. The best ANN architecture for predicting the tribological behavior of unidirectional short castor fiber reinforced epoxy resin composite was found by varying neural network type, no of hidden layers, no of neurons in each hidden layer and transfer function by using trainlm as training function. The optimization flow chart followed for obtaining best ANN architecture for single and multi-hidden layer was presented in Table 15.

Table 15 Optimization flow chart.

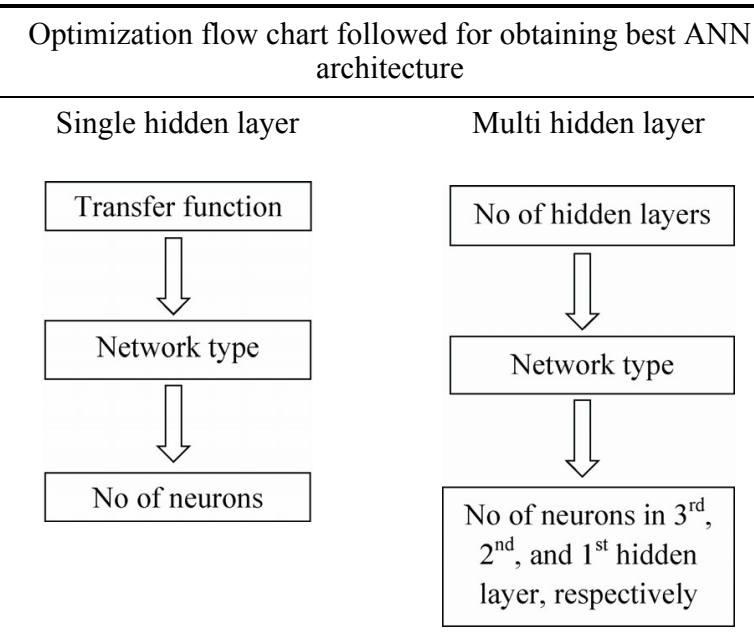

Additionally, the input data was normalized between slightly offset values (0.1-0.9). After the neural network was trained, tested, and simulated successfully, the simulated data was de-normalized corresponded with normalization. The input and output variables were normalized between [0.1, 0.9] and de-normalized as per the formulae given below:

Normalization equation,

$$
P_{\mathrm{n}}=0.1+(0.9-0.1)\left(\frac{P-P_{\min }}{P_{\text {max }}-P_{\text {min }}}\right)
$$


De-normalization equation,

$$
P=\left(P_{\mathrm{n}}-0.1\right)\left(\frac{P_{\max }-P_{\min }}{0.9-0.1}\right)+P_{\min }
$$

where $P_{\mathrm{n}}, P_{\max }$ and $P_{\min }$ are the normalized, maximum, and minimum values of $P$, respectively, and $P$ is the de-normalized value of $P_{\mathrm{n}}$.

The mean square error (MSE) was considered as a measurement criteria for a training set and the formula for the same is given in Eq. (3). The test data was used to validate the network prediction capabilities. Test data presented to the trained network undergoes many iterations till the convergence criteria was satisfied and gives testing output results (predicted results). The error in the network response is calculated by comparing the predicted result with the actual result. Average error\% and standard deviation for a particular network based on predicted test data was also calculated and the formulae for the same were given in Eqs. (4) and (5). Average total error\% for representing upper deviation and lower deviation was calculated using Eq. (6).

$$
\begin{aligned}
& \text { MSE }=\sum_{i=1}^{n}(\hat{Y}-Y)^{2} \\
& \text { Avg error } \%, Z=\left\{\sum_{t=1}^{n}\left[\frac{(x-X) \times 100}{\text { Actual }}\right]\right\} / N \\
& \mathrm{SD}=\left[\frac{\sum(Z-\hat{Z})^{2}}{N-1}\right]^{1 / 2}
\end{aligned}
$$

$$
\text { Avg total error } \%=Z \pm S D
$$

where $i$ is the number of iterations from 1 to $n ; Y$ is predicted value and $\hat{Y}$ is true value during validation, respectively. $N$ is no of test data, $x$ is predicted value, and $X$ is experimental value, respectively during testing. $Z$ is average error\% and $\hat{Z}$ is mean of average error\% of test data, respectively.

Among various ANN models, ANN with bkpropagation learning algorithm had become the most popular model in engineering applications. Therefore, two back-propagation (feed-forward and cascadeforward) networks and layer recurrent networks were used in the present work. However, the performance of the network depends on the number of hidden layers and number of neurons. As there is no specific rule for selecting number of neurons and hidden layers, networks with different architectures are tested by trial and error and the network with the highest performance has been chosen. Hence, the optimization of ANN architecture is carried out to find the best predicted results. Once the optimal ANN architecture is designed and trained efficiently, then it can be recalled to do the prediction of the tribological performance. A preliminary investigation (Network Nos. 1-18) was carried out to find the best transfer function using single hidden layer (SHL) with 9 and 10 neurons and the data was presented in

\begin{tabular}{|c|c|c|c|c|c|c|c|c|c|c|c|}
\hline \multirow{2}{*}{$\begin{array}{c}\text { Network } \\
\text { No. }\end{array}$} & \multirow{2}{*}{ Network type } & \multirow{2}{*}{$\begin{array}{l}\text { Training } \\
\text { function }\end{array}$} & \multirow{2}{*}{$\begin{array}{l}\text { No. of } \\
\text { layers }\end{array}$} & \multirow{2}{*}{$\begin{array}{l}\text { No. of } \\
\text { neurons }\end{array}$} & \multirow{2}{*}{$\begin{array}{l}\text { Transfer } \\
\text { function }\end{array}$} & \multicolumn{2}{|l|}{ Wear } & \multicolumn{2}{|l|}{ Temp } & \multicolumn{2}{|l|}{$\mathrm{CoF}$} \\
\hline & & & & & & Avg error $\%$ & SD & Avg error $\%$ & $\mathrm{SD}$ & Avg error $\%$ & SD \\
\hline 1 & Cascade forward back prop & Trainlm & 1 & 9 & Logsig & 25.86 & 39.29 & 3.46 & 5.36 & 16.51 & 23.42 \\
\hline 2 & Cascade forward back prop & Trainlm & 1 & 9 & Purelin & -0.40 & 5.46 & 0.11 & 0.57 & 1.16 & 2.88 \\
\hline 3 & Cascade forward back prop & Trainlm & 1 & 9 & Transig & 0.08 & 10.63 & -0.08 & 1.32 & 3.73 & 6.51 \\
\hline 4 & Feed forward back prop & Trainlm & 1 & 9 & Logsig & 25.87 & 39.24 & 3.93 & 5.28 & 16.07 & 23.36 \\
\hline 5 & Feed forward back prop & Trainlm & 1 & 9 & Purelin & -2.48 & 7.34 & -0.05 & 0.65 & 1.49 & 3.03 \\
\hline 6 & Feed forward back prop & Trainlm & 1 & 9 & Transig & -4.53 & 9.20 & -1.80 & 3.30 & 2.51 & 4.16 \\
\hline 7 & Layer recurrent & Trainlm & 1 & 9 & Logsig & 28.55 & 39.84 & 3.56 & 5.34 & 17.58 & 23.56 \\
\hline 8 & Layer recurrent & Trainlm & 1 & 9 & Purelin & -1.25 & 7.57 & 0.21 & 0.66 & 2.02 & 3.56 \\
\hline 9 & Layer recurrent & Trainlm & 1 & 9 & Transig & 0.16 & 9.60 & -0.02 & 1.74 & 0.79 & 3.84 \\
\hline 10 & Cascade forward back prop & Trainlm & 1 & 10 & Logsig & 25.71 & 39.21 & 3.48 & 5.35 & 15.67 & 23.58 \\
\hline
\end{tabular}
Table 16. Based on the average error $\%$ and standard deviation, it was found that Purelin transfer function provided the best results for single hidden layer than

Table 16 Optimizing the transfer function in single hidden layer with 9 and 10 neurons. 


\begin{tabular}{|c|c|c|c|c|c|c|c|c|c|c|c|}
\hline \multirow{3}{*}{$\begin{array}{c}\text { Network } \\
\text { No. }\end{array}$} & \multirow{3}{*}{ Network type } & \multirow{3}{*}{$\begin{array}{l}\text { Training } \\
\text { function }\end{array}$} & \multirow{3}{*}{$\begin{array}{l}\text { No. of } \\
\text { layers }\end{array}$} & \multirow{3}{*}{$\begin{array}{l}\text { No. of } \\
\text { neurons }\end{array}$} & \multirow{3}{*}{$\begin{array}{l}\text { Transfer } \\
\text { function }\end{array}$} & & & & & (Contin & ued) \\
\hline & & & & & & \multicolumn{2}{|l|}{ Wear } & \multicolumn{2}{|l|}{ Temp } & \multicolumn{2}{|l|}{$\mathrm{CoF}$} \\
\hline & & & & & & Avg error $\%$ & SD & Avg error $\%$ & $\overline{\mathrm{SD}}$ & Avg error $\%$ & SD \\
\hline 11 & Cascade forward back prop & Trainlm & 1 & 10 & Purelin & -0.37 & 8.24 & 0.07 & 0.66 & 1.51 & 3.15 \\
\hline 12 & Cascade forward back prop & Trainlm & 1 & 10 & Transig & 5.57 & 8.69 & 0.30 & 1.00 & 4.27 & 6.28 \\
\hline 13 & Feed forward back prop & Trainlm & 1 & 10 & Logsig & 27.16 & 39.29 & 3.64 & 5.33 & 15.99 & 23.47 \\
\hline 14 & Feed forward back prop & Trainlm & 1 & 10 & Purelin & 0.12 & 7.01 & 0.09 & 0.64 & 1.12 & 2.86 \\
\hline 15 & Feed forward back prop & Trainlm & 1 & 10 & Transig & 6.76 & 12.05 & -0.39 & 2.22 & 0.93 & 7.66 \\
\hline 16 & Layer recurrent & Trainlm & 1 & 10 & Logsig & 24.22 & 39.38 & 3.46 & 5.36 & 14.43 & 23.50 \\
\hline 17 & Layer recurrent & Trainlm & 1 & 10 & Purelin & -1.85 & 6.54 & 0.07 & 0.68 & 1.86 & 3.47 \\
\hline 18 & Layer recurrent & Trainlm & 1 & 10 & Transig & 4.79 & 6.06 & 0.16 & 0.88 & 0.48 & 3.61 \\
\hline
\end{tabular}

Tan-Sigmoid and Log-Sigmoid transfer functions. The upper limit and lower limit error\% of wear for each ANN architecture was found using average total error $\%$. The optimization procedure was carried out considering the error $\%$ of wear only as the error $\%$ of interfacial temperature and $\mathrm{CoF}$ were similar for most of the ANN models. Figure 11 represents the average total error\% of wear for Network Nos. 1-18. Based on the average total error\%, Purelin

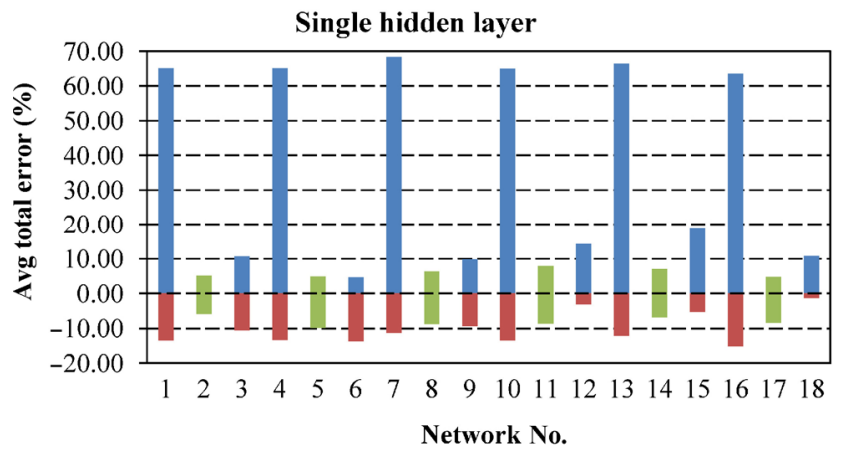

Fig. 11 Average total error $\%$ of wear for SHL-ANN architecture (Network Nos. 1-18). transfer function was found to provide the better results than Tan-Sigmoid and Log-Sigmoid transfer functions.

Now, network type and number of neurons in single hidden layer are optimized for the best prediction of results by considering Purelin as transfer function and the results (Network Nos. 19-41) were shown in Table 17. Also, the average total error\% of wear was presented in Fig. 12. Based on Table 17 and Fig. 12, it can be found that Cascade forward back propagation network with 9 neurons predicted the results accurately than other combinations. Therefore, the optimized network with single hidden layer for best prediction of tribological performance of unidirectional short castor oil fiber reinforced epoxy composites was Cascade forward back propagation network with Trainlm training function, Purelin transfer function, and 9 neurons in hidden layer. The total error\% for optimized network (Network No. 21) was found to be $\pm 5 \%$ for the amount of wear, $\pm 0.5 \%$ for temperature, and $\pm 4 \%$ for the coefficient of friction.

Table 17 Optimizing the network type and number of neurons in single hidden layer.

\begin{tabular}{|c|c|c|c|c|c|c|c|c|c|c|c|}
\hline \multirow{2}{*}{$\begin{array}{c}\text { Network } \\
\text { No. }\end{array}$} & \multirow{2}{*}{ Network type } & \multirow{2}{*}{$\begin{array}{l}\text { Training } \\
\text { function }\end{array}$} & \multirow{2}{*}{$\begin{array}{l}\text { No. of } \\
\text { layers }\end{array}$} & \multirow{2}{*}{$\begin{array}{c}\text { No. of } \\
\text { neurons }\end{array}$} & \multirow{2}{*}{$\begin{array}{l}\text { Transfer } \\
\text { function }\end{array}$} & \multicolumn{2}{|l|}{ Wear } & \multicolumn{2}{|l|}{ Temp } & \multicolumn{2}{|l|}{$\mathrm{CoF}$} \\
\hline & & & & & & Avg error $\%$ & $\mathrm{SD}$ & Avg error $\%$ & $\mathrm{SD}$ & Avg error $\%$ & $\mathrm{SD}$ \\
\hline 19 & Cascade forward back prop & Trainlm & 1 & 7 & Purelin & 0.54 & 6.02 & 0.28 & 1.08 & 2.23 & 4.38 \\
\hline 20 & Cascade forward back prop & Trainlm & 1 & 8 & Purelin & -0.48 & 7.17 & 0.03 & 0.82 & 1.24 & 2.88 \\
\hline 21 & Cascade forward back prop & Trainlm & 1 & 9 & Purelin & -0.40 & 5.04 & 0.11 & 0.57 & 1.16 & 2.58 \\
\hline 22 & Cascade forward back prop & Trainlm & 1 & 10 & Purelin & -0.37 & 8.24 & 0.07 & 0.66 & 1.51 & 3.15 \\
\hline 23 & Cascade forward back prop & Trainlm & 1 & 11 & Purelin & -0.53 & 6.34 & 0.29 & 0.63 & 0.53 & 2.77 \\
\hline 24 & Cascade forward back prop & Trainlm & 1 & 12 & Purelin & 29.03 & 36.19 & -0.03 & 0.99 & -1.77 & 3.08 \\
\hline 25 & Feed forward back prop & Trainlm & 1 & 7 & Purelin & -0.47 & 6.91 & -0.12 & 0.70 & 1.05 & 2.87 \\
\hline
\end{tabular}




\begin{tabular}{|c|c|c|c|c|c|c|c|c|c|c|c|}
\hline \multirow{2}{*}{$\begin{array}{c}\text { Network } \\
\text { No. }\end{array}$} & \multirow{2}{*}{ Network type } & \multirow{2}{*}{$\begin{array}{l}\text { Training } \\
\text { function }\end{array}$} & \multirow{2}{*}{$\begin{array}{l}\text { No. of } \\
\text { layers }\end{array}$} & \multirow{2}{*}{$\begin{array}{l}\text { No. of } \\
\text { neurons }\end{array}$} & \multirow{2}{*}{$\begin{array}{l}\text { Transfer } \\
\text { function }\end{array}$} & \multicolumn{2}{|l|}{ Wear } & \multicolumn{2}{|l|}{ Temp } & \multicolumn{2}{|l|}{$\mathrm{CoF}$} \\
\hline & & & & & & Avg error $\%$ & SD & Avg error $\%$ & $\mathrm{SD}$ & Avg error $\%$ & $\mathrm{SD}$ \\
\hline 26 & Feed forward back prop & Trainlm & 1 & 8 & Purelin & 0.25 & 7.56 & -0.02 & 0.60 & 0.90 & 2.76 \\
\hline 27 & Feed forward back prop & Trainlm & 1 & 9 & Purelin & -2.48 & 7.34 & -0.05 & 0.65 & 1.49 & 3.03 \\
\hline 28 & Feed forward back prop & Trainlm & 1 & 10 & Purelin & 0.12 & 7.01 & 0.09 & 0.64 & 1.12 & 2.86 \\
\hline 29 & Feed forward back prop & Trainlm & 1 & 11 & Purelin & -1.08 & 6.57 & 0.15 & 0.69 & 0.42 & 2.66 \\
\hline 30 & Feed forward back prop & Trainlm & 1 & 12 & Purelin & -0.83 & 7.04 & 0.21 & 0.62 & 1.61 & 3.37 \\
\hline 31 & Feed forward back prop & Trainlm & 1 & 13 & Purelin & -1.30 & 6.86 & -0.17 & 0.82 & 1.09 & 2.74 \\
\hline 32 & Feed forward back prop & Trainlm & 1 & 14 & Purelin & -1.44 & 7.54 & 0.11 & 0.62 & 0.71 & 2.72 \\
\hline 33 & Feed forward back prop & Trainlm & 1 & 15 & Purelin & -1.38 & 5.80 & -0.06 & 0.75 & 1.20 & 2.70 \\
\hline 34 & Layer recurrent & Trainlm & 1 & 7 & Purelin & -0.91 & 6.07 & -0.34 & 0.79 & 1.92 & 3.56 \\
\hline 35 & Layer recurrent & Trainlm & 1 & 8 & Purelin & -0.26 & 6.83 & -0.01 & 0.82 & 0.92 & 2.83 \\
\hline 36 & Layer recurrent & Trainlm & 1 & 9 & Purelin & -1.25 & 7.57 & 0.21 & 0.66 & 2.02 & 3.56 \\
\hline 37 & Layer recurrent & Trainlm & 1 & 10 & Purelin & -1.85 & 6.54 & 0.07 & 0.68 & 1.86 & 3.47 \\
\hline 38 & Layer recurrent & Trainlm & 1 & 11 & Purelin & -1.82 & 7.31 & 0.07 & 0.81 & 1.93 & 3.36 \\
\hline 39 & Layer recurrent & Trainlm & 1 & 12 & Purelin & -1.51 & 6.28 & 0.07 & 0.63 & 0.86 & 2.99 \\
\hline 40 & Layer recurrent & Trainlm & 1 & 13 & Purelin & 1.81 & 7.73 & -0.07 & 0.83 & 1.41 & 2.84 \\
\hline 41 & Layer recurrent & Trainlm & 1 & 14 & Purelin & 8.28 & 21.91 & -0.05 & 1.29 & 4.36 & 7.22 \\
\hline
\end{tabular}

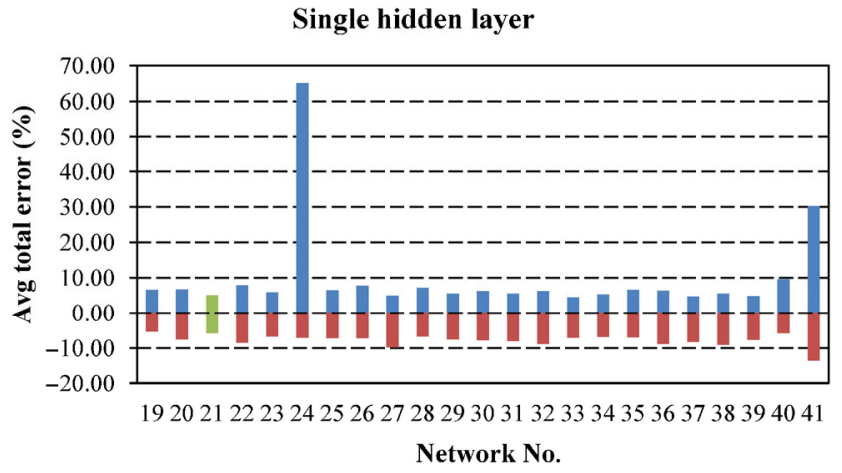

Fig. 12 Average total error\% of wear for SHL-ANN architecture (Network Nos. 19-41).

As mentioned earlier, MSE was considered as a measurement criterion for evaluating the validation performance of ANN model. The MSE of single hidden layer ANN architectures (Network Nos. 1-41) were represented in Fig. 13. The MSE of optimized network (Network No. 21) can be found to be very low indicating that the optimized ANN model captured the nonlinear behavior of experimental data quite well. MSE of optimized network (Network No. 21) was 0.001828 and can be seen in Fig. 14 .

Regression plots for the optimized network (Network No. 21) were represented in Fig. 15. The plots represent

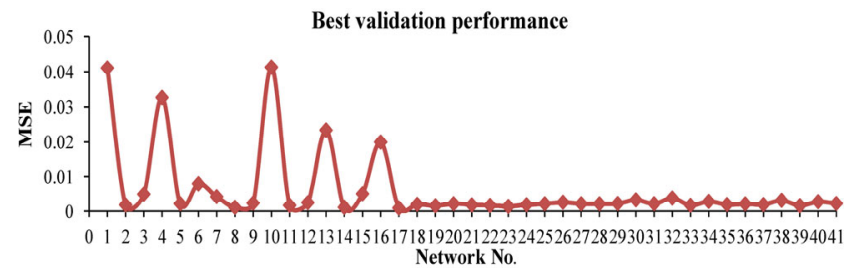

Fig. 13 Mean square error of SHL- ANN architecture (Network Nos. 1-41).

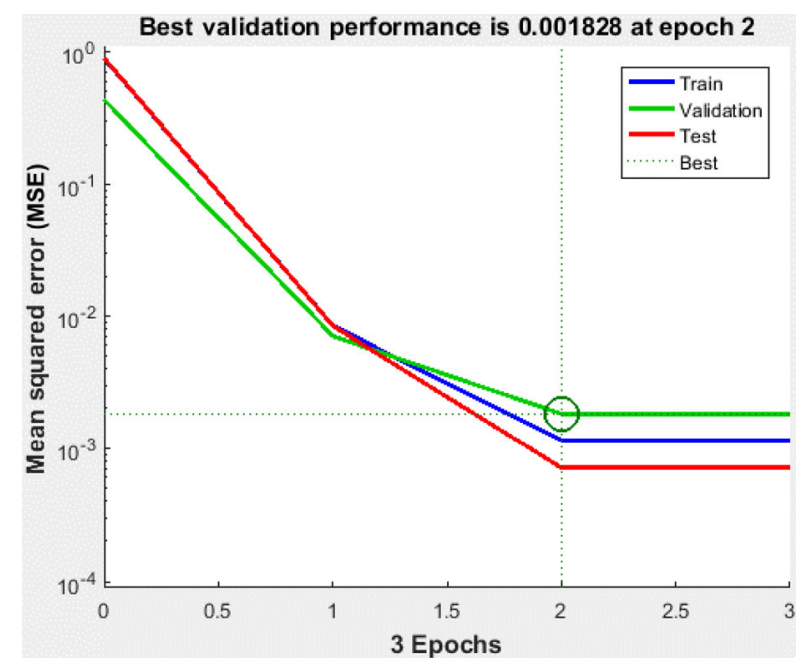

Fig. 14 Performance plot of optimized SHL-ANN architecture (Network No. 21). 

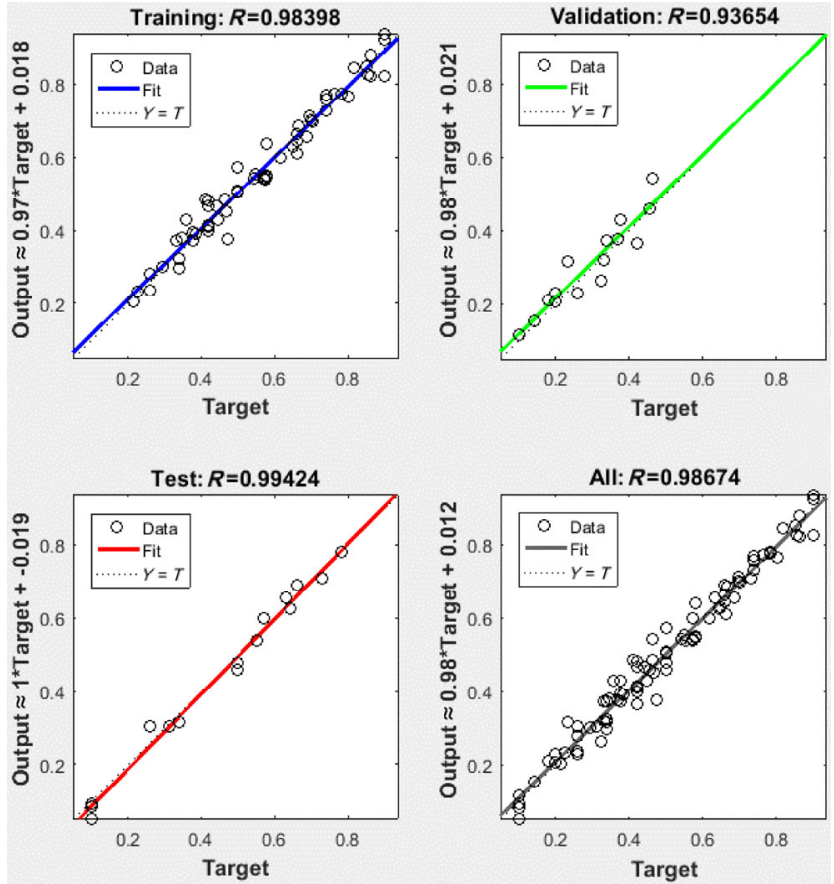

Fig. 15 Regression plot of optimized SHL-ANN architecture (Network No. 21).

the training errors, validation errors, and test errors for the amount of wear, interface temperature, and coefficient of friction. The closeness between the data clusters line with central lines will indicate the accuracy of the model. It can be observed from Fig. 15 that most of the data was closer to the central line which demonstrates that the developed ANN model was more accurate. The overall correlation coefficient was 0.99 , which indicates good agreement between the test results and the SHL-ANN model prediction results. The best linear fit was indicated by a dashed line.

Now the attempt was made to improve the prediction accuracy further using multi hidden layer (MHL) network. By Kolmogorov's theorem, it was reported that any function could be approximated by at most four layers $[37,38]$. Therefore, various ANN architectures in the range from two to four layers were analyzed. Initially, the different networks were tested with 2, 3, and 4 hidden layers with 9 neurons in each hidden layer using Trainlm and Purelin as training and transfer functions, respectively, and the corresponding results (Network Nos. 42-50) were presented in Table 18. Also, the average total error\% of wear was presented in Fig. 16. Considering Table 18 and Fig. 16, it can be found that MHL-ANN architectures with 3 hidden layers predicted the results accurately than those with 2 and 4 hidden layers. It is also found that feed forward back propagation network provided

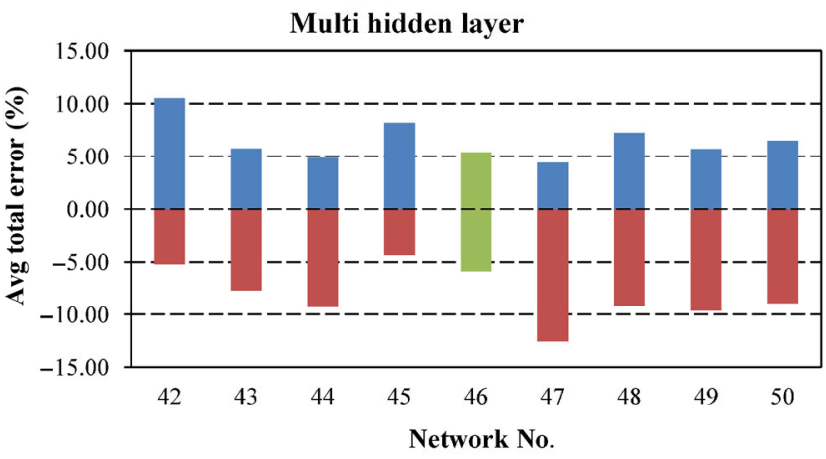

Fig. 16 Average total error\% for MHL-ANN architectures (Network Nos. 42-50).

Table 18 Optimizing the network type and number of multi hidden layers.

\begin{tabular}{|c|c|c|c|c|c|c|c|c|c|c|c|}
\hline \multirow{2}{*}{$\begin{array}{c}\text { Network } \\
\text { No. }\end{array}$} & \multirow{2}{*}{ Network type } & \multirow{2}{*}{$\begin{array}{l}\text { Training } \\
\text { function }\end{array}$} & \multirow{2}{*}{$\begin{array}{l}\text { No. of } \\
\text { layers }\end{array}$} & \multirow{2}{*}{$\begin{array}{l}\text { No. of } \\
\text { neurons }\end{array}$} & \multirow{2}{*}{$\begin{array}{l}\text { Transfer } \\
\text { function }\end{array}$} & \multicolumn{2}{|l|}{ Wear } & \multicolumn{2}{|l|}{ Temp } & \multicolumn{2}{|l|}{$\mathrm{CoF}$} \\
\hline & & & & & & Avg error $\%$ & $\mathrm{SD}$ & Avg error $\%$ & $\mathrm{SD}$ & Avg error $\%$ & SD \\
\hline 42 & Cascade forward back prop & Trainlm & 2 & 9,9 & & 2.65 & 7.88 & -0.02 & 0.77 & 0.65 & 2.53 \\
\hline 43 & Cascade forward back prop & Trainlm & 3 & $9,9,9$ & Purelin & -0.98 & 6.73 & -0.01 & 0.74 & 1.59 & 3.16 \\
\hline 44 & Cascade forward back prop & Trainlm & 4 & $9,9,9,9$ & Purelin & -2.21 & 7.07 & 0.00 & 0.64 & 0.88 & 2.83 \\
\hline 45 & Feed forward back prop & Trainlm & 2 & 9,9 & Purelin & 1.92 & 6.25 & 0.11 & 0.64 & 0.61 & 2.68 \\
\hline 46 & Feed forward back prop & Trainlm & 3 & $9,9,9$ & Purelin & -0.26 & 5.64 & -0.11 & 0.81 & 1.30 & 2.97 \\
\hline 47 & Feed forward back prop & Trainlm & 4 & $9,9,9,9$ & Purelin & -4.09 & 8.48 & -0.05 & 0.67 & 1.35 & 3.04 \\
\hline 48 & Layer recurrent & Trainlm & 2 & 9,9 & Purelin & -0.97 & 8.21 & 0.10 & 0.72 & 1.14 & 2.92 \\
\hline 49 & Layer recurrent & Trainlm & 3 & $9,9,9$ & Purelin & -1.98 & 7.66 & 0.25 & 0.66 & 1.48 & 3.15 \\
\hline 50 & Layer recurrent & Trainlm & 4 & $9,9,9,9$ & Purelin & -1.22 & 7.71 & 0.21 & 0.72 & 0.84 & 2.79 \\
\hline
\end{tabular}


the best results in multi hidden layer.

The number of neurons was varied in three hidden layers to find the optimum number of neurons in each layer by considering feed forward back propagation as network type, trainlm as training function and purelin as transfer function, and the results of network Nos. 51 to 73 were shown in Table 19. Also, the average total error\% of wear was presented in Fig. 17. Based on Table 19 and Fig. 17, it can be found that feed forward back propagation network with 9, 13, and 9 neurons in hidden layer 1,2, and 3 respectively, predicted the results accurately than other combinations. Therefore, the optimized network with multi hidden layer for best prediction of tribological performance of unidirectional short castor oil fiber reinforced epoxy composites was feed forward back propagation network with Trainlm training function, Purelin

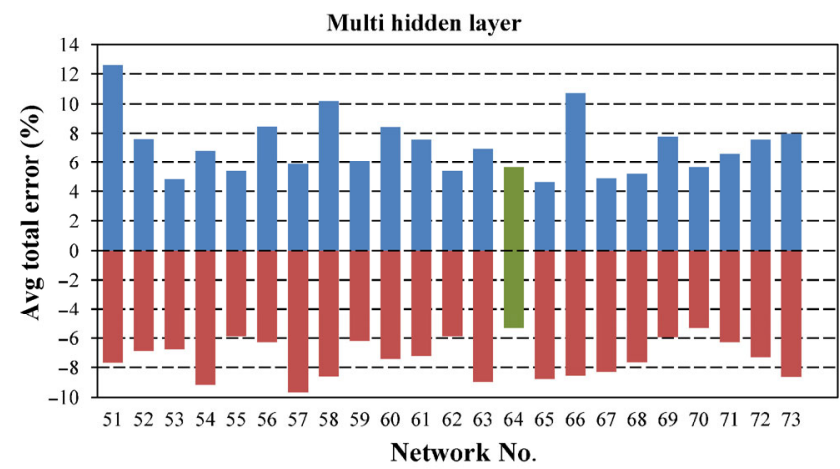

Fig. 17 Average total error\% for multi hidden layer ANN architectures (Network Nos. 51-73).

transfer function, and 9, 13, 9 neurons in each hidden layer, respectively. The total error\% for optimized network (Network No. 64) was found to be $\pm 4.5 \%$ for the amount of wear, $\pm 0.5 \%$ for temperature, and $\pm 3 \%$

Table 19 Optimizing the number of neurons in multi hidden layers.

\begin{tabular}{|c|c|c|c|c|c|c|c|c|c|c|c|}
\hline \multirow{2}{*}{$\begin{array}{c}\text { Network } \\
\text { No. }\end{array}$} & \multirow{2}{*}{ Network type } & \multirow{2}{*}{$\begin{array}{l}\text { Training } \\
\text { function }\end{array}$} & \multirow{2}{*}{$\begin{array}{l}\text { No. of } \\
\text { layers }\end{array}$} & \multirow{2}{*}{$\begin{array}{l}\text { No. of } \\
\text { neurons }\end{array}$} & \multirow{2}{*}{$\begin{array}{l}\text { Transfer } \\
\text { function }\end{array}$} & \multicolumn{2}{|l|}{ Wear } & \multicolumn{2}{|l|}{ Temp } & \multicolumn{2}{|l|}{$\mathrm{CoF}$} \\
\hline & & & & & & Avg error $\%$ & SD & Avg error $\%$ & SD & Avg error $\%$ & SD \\
\hline 51 & Feed forward back prop & Trainlm & 3 & $9,9,1$ & Purelin & 2.44 & 10.13 & -0.23 & 1.07 & 0.57 & 2.54 \\
\hline 52 & Feed forward back prop & Trainlm & 3 & $9,9,3$ & Purelin & 0.35 & 7.25 & -0.16 & 0.77 & 1.12 & 2.88 \\
\hline 53 & Feed forward back prop & Trainlm & 3 & $9,9,5$ & Purelin & -0.97 & 5.81 & 0.15 & 0.61 & 0.91 & 2.85 \\
\hline 54 & Feed forward back prop & Trainlm & 3 & $9,9,7$ & Purelin & -1.19 & 8 & -0.01 & 0.83 & 1.78 & 3.31 \\
\hline 55 & Feed forward back prop & Trainlm & 3 & $9,9,9$ & Purelin & -0.26 & 5.64 & -0.11 & 0.81 & 1.3 & 2.97 \\
\hline 56 & Feed forward back prop & Trainlm & 3 & $9,9,11$ & Purelin & 1.09 & 7.36 & -0.06 & 0.8 & 1.08 & 2.96 \\
\hline 57 & Feed forward back prop & Trainlm & 3 & $9,9,13$ & Purelin & -1.9 & 7.79 & 0.24 & 0.58 & 0.99 & 2.87 \\
\hline 58 & Feed forward back prop & Trainlm & 3 & $9,1,9$ & Purelin & 0.79 & 9.4 & -0.33 & 1.11 & 0.65 & 2.74 \\
\hline 59 & Feed forward back prop & Trainlm & 3 & $9,3,9$ & Purelin & -0.09 & 6.12 & 0.18 & 0.59 & 0.67 & 2.77 \\
\hline 60 & Feed forward back prop & Trainlm & 3 & $9,5,9$ & Purelin & 0.5 & 7.93 & 0.04 & 0.75 & 0.75 & 2.89 \\
\hline 61 & Feed forward back prop & Trainlm & 3 & $9,7,9$ & Purelin & 0.18 & 7.39 & 0.16 & 0.59 & 1.18 & 2.96 \\
\hline 62 & Feed forward back prop & Trainlm & 3 & $9,9,9$ & Purelin & -0.26 & 5.64 & -0.11 & 0.81 & 1.3 & 2.97 \\
\hline 63 & Feed forward back prop & Trainlm & 3 & $9,11,9$ & Purelin & -1.03 & 7.96 & 0.13 & 0.61 & 0.31 & 2.32 \\
\hline 64 & Feed forward back prop & Trainlm & 3 & $9,13,9$ & Purelin & 0.15 & 4.49 & 0.23 & 0.6 & 1.08 & 2.09 \\
\hline 65 & Feed forward back prop & Trainlm & 3 & $9,15,9$ & Purelin & -2.08 & 6.72 & -0.03 & 0.6 & 0.9 & 2.8 \\
\hline 66 & Feed forward back prop & Trainlm & 3 & $1,13,9$ & Purelin & 1.08 & 9.63 & -0.03 & 0.98 & 0.82 & 2.8 \\
\hline 67 & Feed forward back prop & Trainlm & 3 & $3,13,9$ & Purelin & -1.71 & 6.59 & 0.26 & 0.63 & 1.47 & 3.26 \\
\hline 68 & Feed forward back prop & Trainlm & 3 & $5,13,9$ & Purelin & -1.23 & 6.44 & 0.13 & 0.74 & 1.49 & 3.21 \\
\hline 69 & Feed forward back prop & Trainlm & 3 & $7,13,9$ & Purelin & 0.91 & 6.87 & 0.05 & 0.6 & 0.66 & 2.8 \\
\hline 70 & Feed forward back prop & Trainlm & 3 & $9,13,9$ & Purelin & 0.15 & 5.49 & 0.23 & 0.6 & 1.08 & 2.99 \\
\hline 71 & Feed forward back prop & Trainlm & 3 & $11,13,9$ & Purelin & 0.16 & 6.44 & 0.06 & 0.67 & 2.16 & 3.85 \\
\hline 72 & Feed forward back prop & Trainlm & 3 & $13,13,9$ & Purelin & 0.14 & 7.44 & 0.03 & 0.58 & 0.23 & 2.59 \\
\hline 73 & Feed forward back prop & Trainlm & 3 & $13,13,13$ & Purelin & -0.35 & 8.31 & -0.1 & 0.67 & 1.27 & 2.89 \\
\hline
\end{tabular}


for the coefficient of friction.

The MSE of multi hidden layer ANN architectures (Network Nos. 42-73) were represented in Fig. 18. The MSE of optimized network (Network No. 64) can be found to be very low indicating that the optimized ANN model captured the nonlinear behavior of experimental data quite well. MSE of optimized network (Network No. 64) was 0.0011701 and can be seen in Fig. 19. It can be observed that MSE of optimized MHL-ANN architecture (Network No. 64) was 1.56 times lower than that of optimized SHL-ANN architecture (Network No. 21).

Regression plots for the optimized network (Network No. 64) were represented in Fig. 20. The plots represent the training errors, validation errors, and test errors for the amount of wear, interface temperature, and coefficient of friction. It can be observed from Fig. 20 that most of the data was closer to the central line which demonstrates that the developed ANN model was more accurate. The overall correlation coefficient

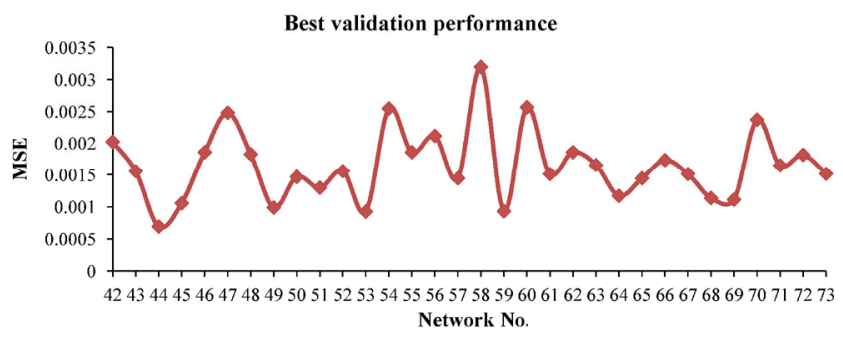

Fig. 18 Mean square error of multi hidden layer ANN architectures (Network Nos. 42-73).

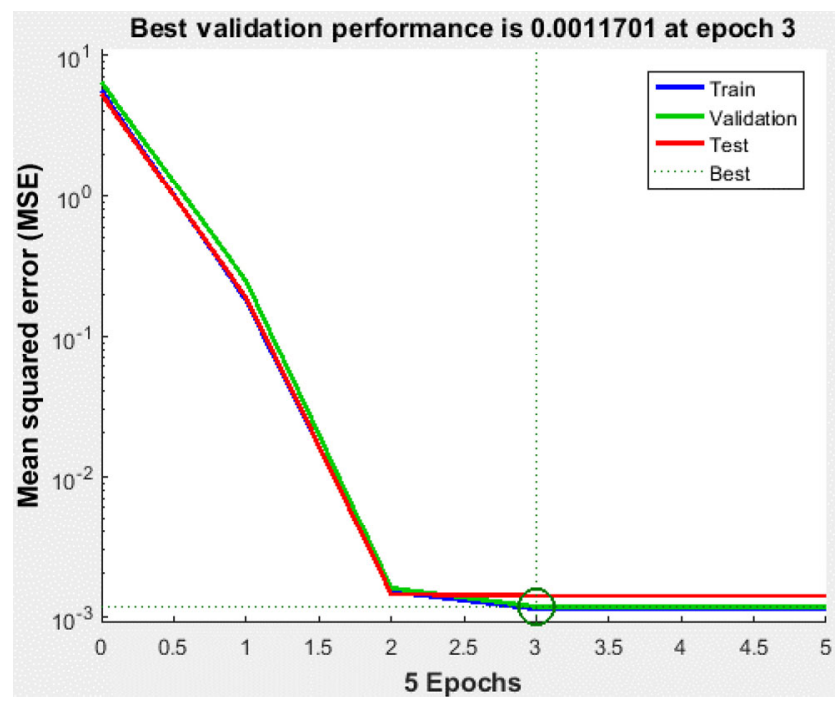

Fig. 19 Performance plot of optimized multi hidden layer ANN architecture (Network No. 64).
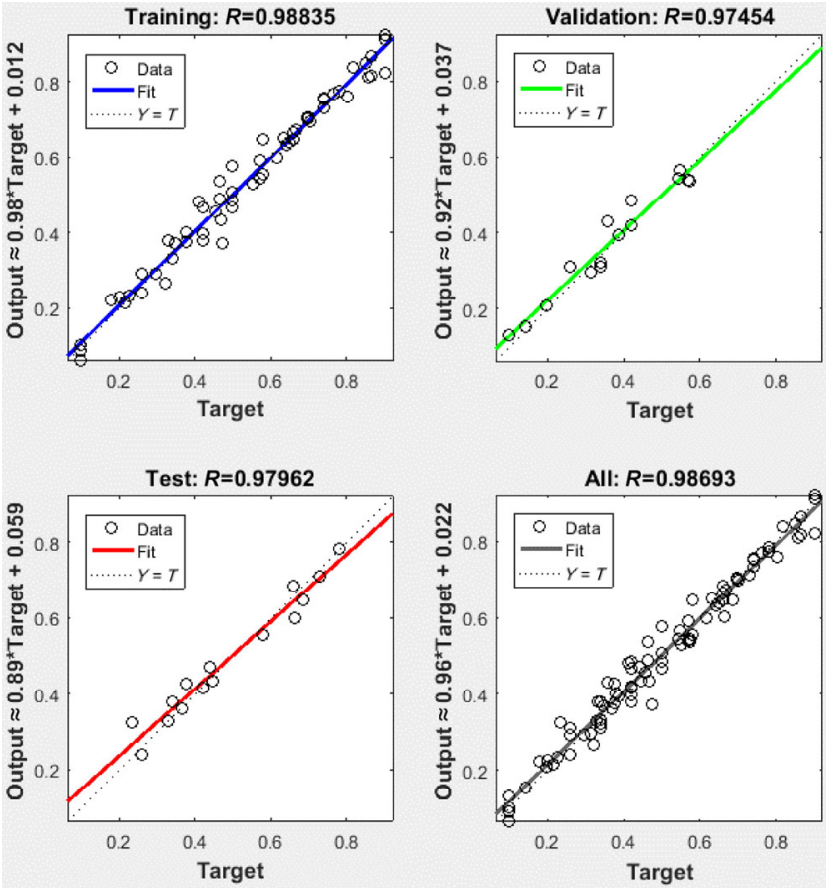

Fig. 20 Regression plot of optimized multi hidden layer ANN architecture (Network No. 64).

was 0.99 , which indicates good agreement between the test results and the MHL-ANN model prediction results. The best linear fit was indicated by a dashed line with high goodness of fit.

The best predicted single and multi hidden layer networks are provided in Table 20. The results emphasize that the generalization ability is the main quality indicator of a neural network, to predict the output of unseen test data accurately. This concludes ANN modeling delivers useful information from relatively small experimental databases, leading to savings in material, cost, and time. Cascade forward back propagation network was found to provide better estimate of results for single hidden layer, whereas feed forward back propagation network was found to provide better estimate of results for multi hidden layer. Purelin transfer function with trainlm training function predicted best results in both single and multi hidden layers. The results depicted in Table 18 were within the acceptable range and hence can be used for predicting the results of unknown data of unidirectional short castor oil fiber reinforced epoxy composites. The confirmation results provided in Section 3.7 shows the reliability of ANN prediction models. 
Table 20 Best predicted network for SHL-ANN and MHL-ANN architectures.

\begin{tabular}{|c|c|c|c|c|c|c|c|c|c|c|}
\hline \multirow{2}{*}{ Network type } & \multirow{2}{*}{$\begin{array}{l}\text { Training } \\
\text { function }\end{array}$} & \multirow{2}{*}{$\begin{array}{l}\text { Hidden } \\
\text { layers }\end{array}$} & \multirow{2}{*}{$\begin{array}{l}\text { No. of } \\
\text { neurons }\end{array}$} & \multirow{2}{*}{$\begin{array}{l}\text { Transfer } \\
\text { function }\end{array}$} & \multicolumn{2}{|l|}{ Wear } & \multicolumn{2}{|l|}{ Temp } & \multicolumn{2}{|l|}{$\mathrm{CoF}$} \\
\hline & & & & & Avg error $\%$ & $\mathrm{SD}$ & Avg error $\%$ & $\overline{\mathrm{SD}}$ & Avg error $\%$ & $\mathrm{SD}$ \\
\hline Cascade forward back prop & Trainlm & 1 & 9 & Purelin & -0.40 & 5.04 & 0.11 & 0.57 & 1.16 & 2.58 \\
\hline Feed forward back prop & Trainlm & 3 & $9,13,9$ & Purelin & 0.15 & 4.49 & 0.23 & 0.6 & 1.08 & 2.09 \\
\hline
\end{tabular}

\subsection{Confirmation tests}

The results obtained from the best single and multi hidden layers ANN models are compared with the linear regression results and experimental results.
From Tables 21-23, it is obvious that ANN model predicted the results with less error than the regression model. Therefore, ANN models were found to be more precise than the linear regression models. Within the ANN models, SHL-ANN model was found to

Table 21 Confirmatory tests for the amount of wear.

\begin{tabular}{|c|c|c|c|c|c|c|c|c|c|}
\hline \multirow{3}{*}{ FL } & \multirow{3}{*}{ Load } & \multirow{3}{*}{ SD } & \multirow{3}{*}{$\begin{array}{l}\text { Experimental } \\
\text { results }\end{array}$} & \multicolumn{6}{|c|}{ Prediction } \\
\hline & & & & \multicolumn{2}{|c|}{ Regression } & \multicolumn{2}{|c|}{ SHL-ANN } & \multicolumn{2}{|c|}{ MHL-ANN } \\
\hline & & & & $\begin{array}{l}\text { Predicted } \\
\text { results }\end{array}$ & Error\% $\%$ & Pred & Error\% $\%$ & Pred & Error\% \\
\hline 5 & 25 & 2,500 & 3.45 & 3.733 & 8.20 & 3.637 & 5.42 & 3.605 & 4.49 \\
\hline 5 & 40 & 2,700 & 5.18 & 5.124 & -1.08 & 5.172 & -0.15 & 5.207 & 0.52 \\
\hline 10 & 35 & 2,500 & 4.90 & 4.915 & 0.31 & 4.861 & -0.80 & 4.88 & -0.41 \\
\hline 15 & 25 & 1,500 & 3.74 & 3.802 & 1.66 & 3.782 & 1.12 & 3.786 & 1.23 \\
\hline 20 & 40 & 2,800 & 5.86 & 6.188 & 5.60 & 6.067 & 3.53 & 6.050 & 3.24 \\
\hline
\end{tabular}

Table 22 Confirmatory tests for temperature.

\begin{tabular}{|c|c|c|c|c|c|c|c|c|c|}
\hline \multirow{3}{*}{ FL } & \multirow{3}{*}{ Load } & \multirow{3}{*}{ SD } & \multirow{3}{*}{$\begin{array}{l}\text { Experimental } \\
\text { results }\end{array}$} & \multicolumn{6}{|c|}{ Prediction } \\
\hline & & & & \multicolumn{2}{|c|}{ Regression } & \multicolumn{2}{|c|}{ SHL-ANN } & \multicolumn{2}{|c|}{ MHL-ANN } \\
\hline & & & & $\begin{array}{l}\text { Predicted } \\
\text { results }\end{array}$ & Error\% $\%$ & Pred & Error\% $\%$ & Pred & Error\% \\
\hline 5 & 25 & 2,500 & 26 & 26.132 & 0.51 & 26.104 & 0.40 & 26.085 & 0.33 \\
\hline 5 & 40 & 2,700 & 27 & 27.366 & 1.35 & 27.308 & 1.14 & 27.298 & 1.10 \\
\hline 10 & 35 & 2,500 & 27 & 27.441 & 1.63 & 27.397 & 1.47 & 27.39 & 1.44 \\
\hline 15 & 25 & 1,500 & 27 & 26.783 & -0.80 & 26.805 & -0.72 & 26.835 & -0.61 \\
\hline 20 & 40 & 2,800 & 29 & 29.043 & 0.15 & 29.017 & 0.06 & 29.034 & 0.12 \\
\hline
\end{tabular}

Table 23 Confirmatory tests for CoF.

\begin{tabular}{|c|c|c|c|c|c|c|c|c|c|}
\hline \multirow{3}{*}{ FL } & \multirow{3}{*}{ Load } & \multirow{3}{*}{ SD } & \multirow{3}{*}{$\begin{array}{l}\text { Experimental } \\
\text { results }\end{array}$} & \multicolumn{6}{|c|}{ Prediction } \\
\hline & & & & \multicolumn{2}{|c|}{ Regression } & \multicolumn{2}{|c|}{ SHL-ANN } & \multicolumn{2}{|c|}{ MHL-ANN } \\
\hline & & & & $\begin{array}{l}\text { Predicted } \\
\text { results }\end{array}$ & Error\% $\%$ & Pred & Error\% & Pred & Error\% $\%$ \\
\hline 5 & 25 & 2,500 & 0.318 & 0.308 & -3.14 & 0.309 & -2.83 & 0.31 & -2.52 \\
\hline 5 & 40 & 2,700 & 0.378 & 0.381 & 0.79 & 0.380 & 0.53 & 0.38 & 0.53 \\
\hline 10 & 35 & 2,500 & 0.369 & 0.376 & 1.90 & 0.375 & 1.63 & 0.376 & 1.90 \\
\hline 15 & 25 & 1,500 & 0.345 & 0.332 & -3.77 & 0.333 & -3.48 & 0.335 & -2.90 \\
\hline 20 & 40 & 2,800 & 0.455 & 0.448 & -1.54 & 0.448 & -1.54 & 0.449 & -1.32 \\
\hline
\end{tabular}


predict the results with less error than the MHL-ANN model. ANN models thus demonstrated as a feasible, reliable, and an effective way for predicting the tribological behavior of unidirectional short castor oil fiber reinforced epoxy resin composite.

\section{Conclusions}

The extraction of castor oil fiber from plant stalk and fabrication of epoxy composites with short castor oil fiber of $40 \%$ volume fraction with different fiber lengths was successful. Experimental investigations and predictions of tribological performance of developed epoxy composites are summarized. The chopped fiber length of $5 \mathrm{~mm}$ has produced good tribological results than those of 10,15 , and $20 \mathrm{~mm}$ when sliding against stainless steel under dry sliding conditions. Hence, $5 \mathrm{~mm}$ fiber length can be considered as the best fiber length among 5-20 mm fiber lengths for the best tribological performance. The lowest wear of $2.05 \mathrm{mg}$ and the lowest $\mathrm{CoF}$ of 0.239 were observed for $5 \mathrm{~mm}$ fiber length. The fiber length of the composite is proportionate to the amount of wear, $\mathrm{CoF}$, and interfacial temperature. ANOVA results indicated that load is the highly influential parameter affecting the amount of wear, $\mathrm{CoF}$, and interfacial temperature followed by fiber length and sliding distance. Addition of $40 \mathrm{vol} \%$ unidirectional short $5 \mathrm{~mm}$-fiber length castor oil fibers improved the wear of epoxy by $65 \%$ to $70 \%$, CoF by $31 \%$ to $40 \%$, and interfacial temperature by $19 \%$ to $24 \%$. The morphology of worn surfaces of the composites was also studied. The SEM image of $5 \mathrm{~mm}$ fiber length composite showed good fiber and matrix interface. Thus, the results emphasize that short castor oil fiber reinforced epoxy composites with $5 \mathrm{~mm}$ fiber length produce better tribological performance, can better suit for tribological material replacement of conventional materials in automotive and structural industries. The wear behavior of the composites was predicted using regression, ANN-single hidden layer, and ANNmulti hidden layer models. Regression equations were developed with good fit and several attempts were made to obtain the best ANN architecture with single and multihidden layers. Regression models predicted the results with $\pm 8 \%$. Cascade forward back propagation network with architecture $3-[9]_{1}-3$,
Trainlm and Purelin as training and transfer functions, respectively, provided the best prediction results in single hidden layer model with $\pm 5 \%$. Feed forward back propagation network with architecture 3-[9] $[13]_{2}-[9]_{3}-3$, Trainlm and Purelin as training and transfer functions, respectively, provided the best prediction results in multi hidden layer model with $\pm 4.5 \%$. ANN with multi hidden layer architecture was found to predict the tribological performance quite well followed by ANN with single hidden layer architecture and regression models. The developed prediction models have higher efficiency and reliability to analyze the tribological performance of unknown data for the fabricated composites.

Open Access This article is licensed under a Creative Commons Attribution 4.0 International Li-cense, which permits use, sharing, adaptation, distribution and reproduction in any medium or for-mat, as long as you give appropriate credit to the original author(s) and the source, provide a link to the Creative Commons licence, and indicate if changes were made.

The images or other third party material in this article are included in the article's Creative Commons licence, unless indicated otherwise in a credit line to the material. If material is not in-cluded in the article's Creative Commons licence and your intended use is not permitted by statutory regulation or exceeds the permitted use, you will need to obtain permission directly from the copyright holder.

To view a copy of this licence, visit http://creativecommons.org/licenses/by/4.0/.

\section{References}

[1] Nozawa J I, Komoto T, Kawai T, Kumehara H. Tribological properties of polymer-sheet-adhered metal hybrid gear. Wear 266(9-10): 893-897 (2009)

[2] Holbery J, Houston D. Natural-fiber-reinforced polymer composites in automotive applications. JOM 58(11): 80-86 (2006)

[3] Mohammed L, Ansari M N M, Pua G, Jawaid M, Islam M $\mathrm{S}$. A review on natural fiber reinforced polymer composite and its applications. Int J Polym Sci 2015: 243947 (2015)

[4] Dwivedi U K, Chand N. Influence of fiber orientation on friction and sliding wear behaviour of jute fiber reinforced polyester composite. Appl Compos Mater 16(2): 93-100 (2009) 
[5] Bajpai P K, Singh I, Madaan J. Tribological behavior of natural fiber reinforced PLA composites. Wear 297(1-2): 829-840 (2013)

[6] Basumatary K K, Mohanta N, Acharya S K. Effect of fiber loading on abrasive wear behaviour of Ipomoea carnea reinforced epoxy composite. Int J Plast Technol 18(1): 64-74 (2014)

[7] Nirmal U, Hashim J, Low K O. Adhesive wear and frictional performance of bamboo fibres reinforced epoxy composite. Tribol Int 47: 122-133 (2012)

[8] Chin C W, Yousif B F. Potentialof kenaf fibres as reinforcement for tribological applications. Wear 267(9-10): 1550-1557 (2009)

[9] Rashid B, Leman Z, Jawaid M, Ghazali M J, Ishak M R, Abdelgnei M A. Dry sliding wear behavior of untreated and treated sugar palm fiber filled phenolic composites using factorial technique. Wear 380-381: 26-35 (2017)

[10] Shalwan A, Yousif B F. Influenceof date palm fiber and graphite filler on mechanical and wear characteristics of epoxy composites. Mater Des 59: 264-273 (2014)

[11] Yousif B F, Lau S T W, Mc William S. Polyester composite based on betelnut fibre for tribological applications. Tribol Int 43(1-2): 503-511 (2010)

[12] Chand N, Dwivedi U K. Sliding wear and friction characteristics of sisal fiber reinforced polyester composites: Effect of silane coupling agent and applied load. Polym Compos 29(3): 280-284 (2008)

[13] Shuhimi F F, Abdollah F M B, Kalam A, Hassan M, Mustafa A E, Amiruddin H. Tribological characteristics comparison for oil palm fibre/epoxy and kenaf fibre/epoxy composites under dry sliding conditions. Tribol Int 101: 247-254 (2016)

[14] Liu Y C, Xie J, Wu N, Wang L D, Ma Y H, Tong J. Influence of silane treatment on the mechanical, tribological, and morphological properties of corn stalk fiber reinforced polymer composites. Tribol Int 131: 398-405 (2019)

[15] Kumar S, Patel V K, Mer K K S, Gangil B, Singh T, Fekete G. Himalayan natural fiber-reinforced epoxy composites: Effect of grewia optiva/bauhinia vahlii fibers on physicomechanical and dry sliding wear behavior. J Nat Fibers (2019) doi: 10.1080/15440478.2019.1612814 (in press)

[16] Patel V K, Chauhan S, Katiyar J K. Physico-mechanical and wear properties of novel sustainable sour-weed fiber reinforced polyester composites. Mater Res Express 5(4) (2018)

[17 Pattanaik A, Prasad M, Mishra S C. Dry sliding wear behavior of epoxy fly ash composite with Taguchi optimization. Eng Sci Technol Int J 19(2): 710-716 (2016)

[18] Khun N W, Zhang H, Lim L H, Yue C Y, Hu X, Yang J L.
Tribological properties of short carbon fibers reinforced epoxy composites. Friction 2(3): 226-239 (2014)

[19] El-Tayeb N S M. A study on the potential of sugarcane fibers/polyester composite for tribological applications. Wear 265(1-2): 223-235 (2008)

[20] El-Tayeb N S M. Abrasive wear performance of untreated SCF reinforced polymer composite. J Mater Process Technol 206(1-3): 305-314 (2008)

[21] El-Tayeb N S M. Development and characterisation of low-cost polymeric composite materials. Mater Des 30(4): 1151-1160 (2009)

[22] Mylsamy K, Rajendran I. Influence of fiber length on the wear behaviour of chopped agave americana fiber reinforced epoxy composites. Tribol Lett 44(1): 75-80 (2011)

[23] Boopathi L, Sampath P S, Mylsamy K. Influence of fiber length in the wear behaviour of borassus fruit fiber reinforced epoxy composites. Int J Eng Sci Technol 4(9): 4119-4129 (2012)

[24] Biswal S, Satapathy A. Preparation, properties and wear performance evaluation of epoxy-palmyra fiber composites. Polym Compos 39(6): 1827-1834 (2018)

[25] Parikh H H, Gohil P P. Experimental investigation and prediction of wear behavior of cotton fiber polyester composites. Friction 5(2): 183-193 (2017)

[26] Satapathy A, Tarkes D P, Nayak N B. Wear response prediction of $\mathrm{TiO}_{2}$-polyester composites using neural networks. Int J Plast Technol 14(S1): 24-29 (2010)

[27] Fathy A, Megahed A A. Predictionof abrasive wear rate of in situ $\mathrm{Cu}-\mathrm{Al}_{2} \mathrm{O}_{3}$ nanocomposite using artificial neural networks. Int J Adv Manuf Technol 62(9-12): 953-963 (2012)

[28] Jiang Z Y, Zhang Z, Friedrich K. Prediction on wear properties of polymer composites with artificial neural networks. Compos Sci Technol 67(2): 168-176 (2007)

[29] Canakci A, Ozsahin S, Varol T. Prediction of effect of reinforcement size and volume fraction on the abrasive wear behavior of AA2014/B4Cp MMCs using artificial neural network. Arab J Sci Eng 39(8): 6351-6361 (2014)

[30] Stojanović B, Vencl A, Bobić I, Miladinović S, Skerlić J. Experimental optimisation of the tribological behaviour of $\mathrm{Al} / \mathrm{SiC} / \mathrm{Gr}$ hybrid composites based on Taguchi's method and artificial neural network. J Brazilian Soc Mech Sci Eng 40(6): 311 (2018)

[31] Saravanan S D, Senthilkumar M. Prediction of tribological behaviour of rice husk ash reinforced aluminum alloy matrix composites using artificial neural network. Russ J Non-Ferr Met 56(1): 97-106 (2015)

[32] Kranthi G, Satapathy A. Evaluation and prediction of wear response of pine wood dust filled epoxy composites using neural computation. Comput Mater Sci 49(3): 609-614 (2010) 
[33] Hassan A F F, Mohammed L S, Abdulsamad H J. Experimental and artificial neural network ANN investigation of bending fatigue behavior of glass fiber/polyester composite shafts. J Brazilian Soc Mech Sci Eng 40(4): 201 (2018)

[34] Chun M S, Biglou J, Lenard J G, Kim J G. Using neural networks to predict parameters in the hot working of aluminum alloys. J Mater Process Technol 86(1-3): 245-251 (1999)

[35] Hassan A M, Alrashdan A, Hayajneh M T, Mayyas A T. Prediction of density, porosity and hardness in aluminumcopper-based composite materials using artificial neural

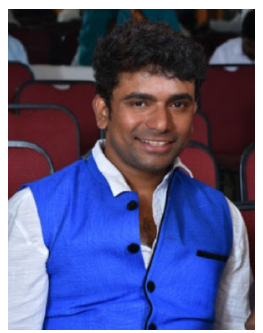

Rajesh EGALA. He received his B.Tech. degree from Viswanadha Institute of Technology and Management College of Engineering, Visakhapatnam, India, and M.Tech. degree from Jawaharlal Nehru Technological

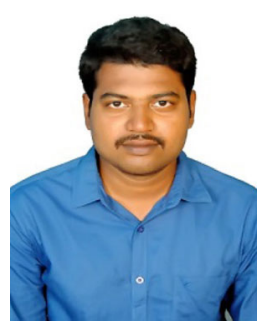

G V JAGADEESH. He received his B.Tech. degree from Vellore Insitute of Technology (VIT) University, Vellore, India, and M.Tech. degree from National Institute of Technology Raipur, India, in 2015

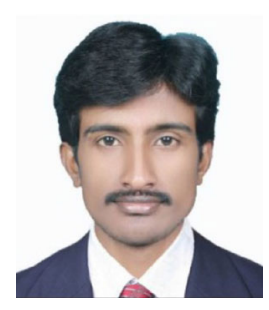

Srinivasu Gangi SETTI. He received his M.Tech. and Ph.D. degrees in mechanical engineering from National Institute of Technology, Warangal, India, in 2009 and 2013, respectively. He is presently working network. J Mater Process Technol 209(2): 894-899 (2009)

[36] Alambeigi F, Khadem S M, Khorsand H, Hasan E M S. A comparison of performance of artificial intelligence methods in prediction of dry sliding wear behavior. Int $J$ Adv Manuf Technol 84(9-12): 1981-1994 (2016)

[37] Kůrková V. Kolmogorov's theorem is relevant. Neural Comput 3(4): 617-622 (1991)

[38] Swingler K. Applying Neural Networks: A practical guide. San Francisco (USA): Morgan Kaufman Publishers Inc., 1996.

University, Kakinada, India, in 2007 and 2010, respectively. He is currently pursuing Ph.D. in the area of natural fiber reinforced composites, development, and its mechanical and tribological behavior in Mechanical Engineering Department of National Institute of Technology Raipur, India.

and 2019, respectively. He is currently pursuing Ph.D. in the area of bio-materials, natural fiber reinforced composites, and their mechanical and tribological studies in Mechanical Engineering Department at National Institute of Technology, Raipur, India.

as assistant professor in the Department of Mechanical Engineering of National Institute of Technology, Raipur, India. His research areas cover the tribological studies of titanium alloys, composites, functionally graded materials, and magnesium alloys. 